\title{
Descentralização e resultados na saúde infantil no Brasil
}

\author{
Dércio Nonato Chaves de Assis ${ }^{1}$
}

\section{Resumo}

Ao longo da última década, o Brasil experimentou um aumento acentuado na descentralização dos serviços de saúde pública. Dado a possibilidade de respostas heterogêneas e consequências distribucionais, buscou-se verificar os impactos gerais e regionais da descentralização dos serviços de saúde pública sobre resultados da saúde infantil nos estados brasileiros no período de 2000 a 2013. Para tanto, construiu-se uma medida de descentralização fiscal do setor de saúde ainda não explorada na literatura nacional e aplicou-se a abordagem do modelo bidirecional de efeitos fixos com tendências estado-específicas e erros padrões robustos. Os resultados demonstraram que a descentralização fiscal das ações e serviços públicos de saúde tiveram, no período estudado, impacto estatisticamente considerável na redução das taxas de mortalidade infantil e na infância no Brasil. Contudo, o impacto da descentralização é diferenciado dado o nível de desenvolvimento regional, com efeitos maiores em regiões mais desenvolvidas (região Sul, -0.598). Ao passo que a capacidade institucional de gestão do setor de saúde dos estados e municípios da região Norte do Brasil (efeito nulo) precisa ser reexaminada.

\section{Palavras-Chave}

Descentralização. Saúde infantil. Desenvolvimento regional. Brasil.

\begin{abstract}
Over the past decade, Brazil experienced a sharp increase in the decentralization of public health services. Given the possibility of heterogeneous responses and distributional consequences, it was sought to verify the general and regional effects of the decentralization of public health services on child health outcomes across Brazilian states during the period 2000-2013. For this, I constructed a measure of fiscal decentralization of the health sector does not explored in national literature and the two-way fixed effects model approach was applied with state-specific
\end{abstract}

- Artigo agraciado com Menção Honrosa no X Prêmio SOF de Monografias da Secretaria de Orçamento Federal, Ministério do Planejamento, Desenvolvimento e Gestão. O autor agradece os valiosos comentários e sugestões de Valdemar Neto, Edinaldo Tebaldi, Jordano Rocha, Fabrício Linhares, Flávio Ataliba, dos participantes do $45^{\circ}$ Encontro Nacional de Economia - ANPEC, do parecerista anônimo da revista Estudos Econômicos e em especial do Editor Marcos Yamada Nakaguma. Erros e omissões são de exclusiva responsabilidade do autor.

1 MRes Economics (PhD Pathway) Student. University of Exeter Business School. Rennes Dr, Exeter EX4 4PU. Exeter, England, United Kingdom - E-mail: dc603@exeter.ac.uk

ORCiD: https://orcid.org/0000-0002-7031-5345.

Recebido: 21/06/2018. Aceite: 27/01/2020.

Editor Responsável: Marcos Yamada Nakaguma

(c) (i) (\$) Esta obra está licenciada com uma Licença Creative Commons Atribuição-Não Comercial 4.0 Internacional. 
trends and robust standard errors. The results showed that the fiscal decentralization of actions and public health services had, during the period in analysis, a substantial statistically impact on reducing the infant and child mortality rates in Brazil. However, the effects of decentralization are different given the regional development level, with superior impacts in more developed regions (South region, -0.598 ). Meanwhile, the institutional capacity of health sector management of states and municipalities in the Northern region of Brazil (null effect) needs to be reexamined.

\section{Keywords}

Decentralization. Child health. Regional development. Brazil.

\section{JEL Classification}

H750. H770. 1140.

\section{Introdução}

A partir da Constituição Federal de 1988 e especialmente na década de 1990, o Brasil encaminhou uma série de reformas, ${ }^{1}$ tanto no sentido de atender as maiores demandas políticas com o processo de redemocratização em curso, quanto no intuito de conquistar a estabilidade macroeconômica. Dentre as ações mais importantes postas em prática, tem-se um novo desenho do federalismo fiscal brasileiro, com aprofundamento da descentralização fiscal e com uma maior autonomia para Estados e Municípios.

Entretanto, a descentralização fiscal ocorrida foi parte de uma tendência mundial, motivada principalmente pelo processo de reestruturação política e reformas econômicas verificadas em diversas localidades. Arzaghi e Henderson (2005), que construíram um índice de federalismo fiscal para 48 países no perído de 1960 a 1995, mostraram que todas as regiões do globo apresentaram tendência de descentralização após os anos 1980. Destacam-se os países latino-americanos que alcançaram o mesmo nível de federalismo que países desenvolvidos em 1995. No caso brasileiro, esse processo não foi planejado e ocorreu especialmente devido aos conflitos que se originaram entre União, Estados e Municípios resultantes da concentração de recursos no governo central imposto pelo regime ditatorial (Guedes e Gasparini 2007). A descentralização seria, assim, a forma de repartir com

1 Entre as principais medidas implementadas pode-se citar a abertura comercial através de redução de tarifas de importação, o controle rígido dos gastos públicos, a privatização de empresas públicas, a liberalização cambial, o estabelecimento de metas inflacionárias, a introdução da Lei de Responsabilidade Fiscal, dentre outras. Essas medidas conseguiram garantir as condições básicas necessárias para estabilidade macroeconômica do país. 
o poder local os déficits acumulados mantendo a legitimidade do Governo Central (Shah e Thompson 2004).

Pode-se imaginar que a maior autonomia fiscal aos governos locais poderia ser vista também como uma ferramenta mais efetiva para as políticas públicas locais, haja vista que possibilitaria as entidades subnacionais implementarem políticas mais direcionadas à melhoria nas condições de vida da população local. Alguns estudos empíricos têm confirmado que o poder local tem uma vantagem informacional maior quando comparada ao poder central, indicando maior capacidade de atender as necessidades dos mais pobres (Galasso e Ravallion 2000; Faguet 2001). Contudo, esses resultados não são observados em todos os casos, não existindo um automatismo de que a descentralização traga necessariamente os retornos esperados.

O sucesso da descentralização depende de um número maior de fatores, tais como: a capacidade financeira e o capital humano local, a clareza nos processos existentes, o grau de maturidade das instituições locais, a competição política e os níveis de informações dos agentes econômicos envolvidos (Collins et al. 2000; Arzaghi e Henderson 2005). Somente a existência desses condicionantes poderia possibilitar que a transferência de poder para as unidades federativas teriam fortes efeitos sobre a prestação dos serviços públicos a sociedade. Dentro desse escopo, a despeito da importância que o acesso a serviços de saúde tem sobre o bem-estar individual e desenvolvimento econômico, ${ }^{2}$ o setor de saúde deve ser considerado um caso especial a ser investigado. Desse modo, a literatura tem dado grande atenção em averiguar a direção dos efeitos da descentralização fiscal dos serviços de saúde sobre os resultados nessa área em um número considerável de países desenvolvidos (no Canadá: Jimenez- Rubio 2011a; na OCDE: Jimenez-Rubio 2011b; na Itália: Cavalieri e Ferrante 2016; na Espanha: Jimenez-Rubio e García-Gomes 2017). Contudo, pouca atenção têm sido despendida em investigar os efeitos da descentralização sobre resultados da saúde em contextos de países em desenvolvimento como o Brasil. Sendo essa, portanto, a primeira motivação para elaboração deste trabalho.

Outra motivação é que a questão de como a descentralização fiscal do setor de saúde pode afetar temporal e espacialmente resultados na saúde encontra-se aberta ao debate. Arze del Granado et al. (2005) encontraram que os gastos em saúde tendem a crescer sua participação nos gastos totais dos

2 Arrow (1963) em artigo seminal, destaca a importância do bom funcionamento do mercado de assistência médica para o bem-estar social. 
governos com a descentralização fiscal. Na medida que esses tipos de gastos têm impacto positivo direto sobre o desenvolvimento do capital humano, seria de se esperar um efeito positivo sobre o bem-estar e desenvolvimento da economia. Soto et al. (2012) utilizando informações de municípios da Colômbia e construindo um indicador de descentralização similar ao utilizado neste estudo, encontram que a descentralização diminui mortalidade infantil. No entanto, os efeitos nos resultados da saúde são assimétricos, dependendo das condições socioeconômicas das localidades.

Nesse contexto, este trabalho busca contribuir para a literatura que investiga a relação entre descentralização e resultados na saúde fornecendo uma avaliação para o Brasil com especial ênfase sobre os impactos na saúde infantil. O Brasil é um excelente caso de estudo, pois além de ter experimentado ao longo da última década um aumento acentuado na descentralização dos serviços de saúde pública, é uma recente democracia com alterações político-institucionais no sistema de saúde (Emenda Constitucional 29 do ano 2000) e um país com pluralidades étnicas, raciais e culturais com regiões exibindo diferentes condições geográficas e econômicas. Além de apresentar taxas de mortalidade infantil e na infância bem superiores a de outros países. ${ }^{3}$ Ademais, é de suma importância estudar novos canais de influência sobre a saúde infantil, já que como afirma Soares (2005) reduções na mortalidade infantil são a principal força por trás do desenvolvimento econômico.

A proposta desta pesquisa é avaliar a partir do modelo bidirecional de efeitos fixos com dummies de tendência estado-específicas e erros padrões robustos a direção dos efeitos da descentralização, mensurada pela proporção entre os gastos de saúde subnacionais (Estadual e Municipal) para o total de gastos de saúde para todos os níveis de governo (Federal, Estadual e Municipal), ${ }^{4}$ sobre saúde infantil no Brasil no período de 2000 a 2013. Para tanto, utilizar-se-ão dados oriundos do Ministério da Saúde do Brasil (DATA-SUS) e do Instituto Brasileiro de Geografia e Estatística (IBGE) para cada um dos 26 Estados brasileiros e o Distrito Federal. ${ }^{5}$ Por fim,

3 Segundo relatório da Organização Mundial da Saúde (Herdando um mundo sustentável: atlas sobre a saúde das crianças e o meio ambiente, 2017, o Brasil registra a taxa de 16,4 mortes de crianças com menos de cinco anos para cada 1.000 nascimentos, acima do índice de países como Austrália $(3,8)$, Argentina $(12,5)$ ou China $(10,7)$, mas com resultados melhores que países da África.

4 Na seção de metodologia tem-se uma melhor descrição da medida de descentralização da saúde utilizada neste estudo.

5 O período utilizado, 2000 a 2013, e a unidade de análise escolhida, são em decorrência da disponibilidade de dados. Especialmente devido às variáveis de gastos em saúde que apresentavam metodologia de cálculo diferente antes dos anos 2000. 
dado que o Brasil é um país que apresenta relevantes disparidades regionais (Assis e Linhares 2018), utilizam-se dummies interativas entre determinada região do país e o indicador de descentralização fiscal da saúde para ter um indicativo da possibilidade de efeitos diferenciados da descentralização sobre resultados na saúde infantil em regiões mais desenvolvidas, vis-à-vis, regiões relativamente mais pobres.

Além desta introdução, este artigo divide-se em mais seis seções. A seção seguinte apresenta uma revisão da literatura, dividida em estudos teóricos e empíricos. A terceira seção exibe uma breve apresentação do arcabouço institucional do sistema de saúde público brasileiro. Na quarta expõe-se a metodologia utilizada no trabalho, apresentação dos dados e modelo econométrico. Na quinta a análise dos resultados. Na sexta, uma breve análise de robustez e sensitividade dos resultados. Por fim, são feitas as considerações finais do estudo.

\section{Revisão de literatura}

A presente seção discute os aspectos teóricos sobre federalismo fiscal apresentando a relação entre descentralização versus centralização como forma de atender as demandas e fornecer melhores serviços públicos à população de uma determinada economia. Bem como busca detalhar alguns dos principais resultados encontrados em trabalhos empíricos anteriores com foco no impacto da descentralização dos serviços de saúde sobre resultados na saúde infantil.

\subsection{Aspectos teóricos}

Sob a ótica dos gastos públicos, a descentralização permite que as despesas sejam realizadas de forma mais próxima às necessidades locais e desse modo pode se ajustar melhor às preferências dos indivíduos. Hayek (1945) e Oates $(1972,2005)$ apresentam os argumentos básicos de que a descentralização possa melhorar o bem-estar social da população local. O ponto central desse raciocínio é que os governos subnacionais têm uma vantagem informacional sobre as circunstâncias locais que autoridades centrais. Além disso, esse ganho informacional resultaria na possibilidade das autoridades locais serem mais exigidas por resultados satisfatórios de suas políticas a 
partir do mecanismo de premiação e punição advindo do processo eleitoral. Isso poderia estabelecer um desenho mais eficiente na gestão dos gastos públicos.

Por outro lado, conforme argumentaram Samuelson (1954) e Musgrave (1959), não é possível determinar um nível eficiente de gasto público de acordo com regras aplicadas ao mecanismo de mercado. Dado que o bem público consumido por um indivíduo não exclui o consumo por outro, então ninguém teria incentivo a revelar sua real demanda por esse tipo de bem, desencadeando o comportamento free-riding. Assim, cada indivíduo preferiria deixar que outros revelassem suas demandas e pagassem pelo bem.

Contudo, Tiebout (1956) demonstra que esse mecanismo pode ser solucionado através da descentralização por meio da comparação entre várias jurisdições. Os cidadãos podem observar a provisão dos bens públicos e com base em suas preferências determinar aquela que lhes proporcionaria maior bem-estar. Os cidadãos migrariam em busca de jurisdições com melhores relações custo-benefício entre taxação e provisão de bens e serviços públicos. Assim, a competição entre as jurisdições por contribuintes e por recursos econômicos móveis provavelmente restringiria os poderes tributários do governo, encorajando a provisão dos bens e serviços públicos locais com custos mais eficientes.

A teoria tradicional tem sido crítica quanto a participação ativa dos governos locais. Essa discordância está centrada especialmente no aspecto da eficiência das políticas públicas locais. Prud'homme (1995) chama atenção ao fato de que a descentralização pode permitir a replicação de estruturas desnecessárias e ineficientes nos governos locais. Ademais, ao tentar melhorar as condições de vida das pessoas pobres em uma determinada localidade, o governo subnacional poderia aumentar a arrecadação própria sobre setores mais ricos, o que eventualmente poderia estimular a migração para outras regiões que apresentam menor taxação. Isso provocaria a erosão da arrecadação ocasionando uma política distributiva ineficiente.

Naturalmente, a magnitude dessa erosão dependeria do grau de mobilidade dos fatores de produção e da população. Quando essa mobilidade é imperfeita ou custosa, os governos locais podem realizar um papel mais importante na introdução de políticas sociais. Desse modo, considerando que em países em desenvolvimento a mobilidade é relativamente baixa, po- 
de-se imaginar que os governos locais teriam maior aptidão na provisão de bens públicos como a saúde. Por outro lado, essa efetividade poderia ser prejudicada dependendo da forma que o federalismo fiscal é desenhado, já que há um trade-off entre a partilha de risco e o risco moral: a partilha de risco federal pode induzir os governos locais a promulgar políticas que aumentam o risco local na presença de captura (risco moral) das capacidades administrativas desses governos na elaboração de políticas. Os arranjos alternativos criam incentivos diferentes para os formuladores de políticas e os eleitores, e dão origem a diferentes equilíbrios políticos. Sob as instituições apropriadas, a centralização das funções e do poder podem mitigar o problema do risco moral (Perrson e Tabellini 1996a).

Por fim, destaca-se que dentro desse arcabouço teórico há possibilidade de distinção de efeitos diretos e indiretos da descentralização fiscal sobre os indicadores de saúde. Os efeitos diretos estariam relacionados, tanto a mudanças na implementação de políticas públicas, como na mudança de comportamento dos agentes econômicos devido à descentralização. Por outro lado, os efeitos indiretos seriam determinados pela interação com a estrutura socioeconômica do país.

\subsection{Estudos empíricos}

De acordo com a seção anterior, há argumentos teóricos que apontam tanto para uma relação positiva entre descentralização e resultados na saúde infantil, como existem também explicações para uma provável relação negativa. Desse modo, diversos estudos empíricos têm procurado analizar a relação entre essas medidas. Esta seção faz um breve resumo dos principais trabalhos disponíveis na literatura, sempre procurando destacar a forma de aferição do indicador de descentralização e das variáveis de controle utilizadas. Destaca-se que é comum aos trabalhos citados o uso da taxa de mortalidade infantil (TMI) como forma de mensurar resultados na saúde. O Quadro 1 apresenta um resumo das evidências dos efeitos da descentralização fiscal sobre a mortalidade infantil. 
Habibi et al (2003) investigam o impacto da descentralização fiscal na Argentina utilizando dados para 23 províncias (Estados) no perído de 1970 a 1994. Eles utilizam duas medidas de descentralização: a proporção das receitas auferidas localmente e a proporção da receita controlada pela província sobre o total, além de: PIB per capita da província, funcionários públicos por 1.000 habitantes e despesas totais da província per capita como controles. Seus resultados mostram que descentralização reduz mortalidade infantil. Além disso, ao comparar os padrões de descentralização entre as províncias de baixa renda e alta renda, evidencia que as disparidades nas TMIs regionais diminuem significativamente durante o período após as reformas de descentralização serem realizadas.

Asfaw et al. (2007), analizando 14 grandes Estados indianos entre 1990 e 1997, observa que a descentralização fiscal reduz a TMI de áreas rurais, e destaca que sua eficácia aumenta com o nível de descentralização política. Para chegar a esses resultados, seu trabalho utiliza três indicadores de descentralização fiscal: a despesa total do Estado, a despesa local total pela população rural e a parcela das receitas próprias locais no total das despesas locais. Além de PIB per capita e alfabetização feminina como variáveis independentes.

Para dados de 15 regiões da Espanha entre 1992 e 2003, Cantarero e Pascual (2008) avaliam os efeitos da descentralização fiscal da saúde (proporção das despesas de saúde dos entes subnacionais em relação à despesa total em saúde para todos os níveis de governo) sobre a TMI e expectativa de vida. Suas estimações mostram que a descentralização fiscal é negativamente relacionada com as TMIs e positivamente relacionada com a expectativa de vida. 


\section{Quadro 1 - Resumo das principais evidências dos efeitos da descentralixzação fiscal sobre a mortalidade infantil}

\begin{tabular}{|c|c|c|c|}
\hline \multicolumn{4}{|c|}{ Lista de Artigos } \\
\hline Estudo & Unidade/Método de Estimação & Medida de Descentralização & Conclusōes \\
\hline $\begin{array}{l}\text { Robalino } \\
\text { et al. }(2001)\end{array}$ & Painel de Países/Efeitos Fixos & $\begin{array}{l}\text { Relação entre as despesas } \\
\text { totais dos governos locais e } \\
\text { as despesas totais do go- } \\
\text { verno central. }\end{array}$ & $\begin{array}{l}\text { Efeito Positivo. Maior efeito } \\
\text { em países pobres. }\end{array}$ \\
\hline $\begin{array}{l}\text { Habibi } \\
\text { et al. (2003) }\end{array}$ & $\begin{array}{l}\text { Argentina ( } 23 \text { províncias)/ } \\
\text { MQO, MQG e Efeitos Fixos }\end{array}$ & $\begin{array}{l}\text { Proporção da receita aufe- } \\
\text { rida localmente e proporção } \\
\text { da receita controlada sobre o } \\
\text { total. }\end{array}$ & Efeito Positivo. \\
\hline $\begin{array}{l}\text { Asfaw } \\
\text { et al. (2007) }\end{array}$ & $\begin{array}{l}\text { India ( } 14 \text { estados)/ Efeitos fixos } \\
\text { e Aleatórios }\end{array}$ & $\begin{array}{l}\text { Índice de descentralização } \\
\text { fiscal obtido por análise fa- } \\
\text { torial com base em três va- } \\
\text { riáveis, a parcela da despesa } \\
\text { local na despesa total do es- } \\
\text { tado, a despesa local total } \\
\text { pela população, a parcela da } \\
\text { receita própria local do total } \\
\text { das despesas locais. }\end{array}$ & Efeito Positivo. \\
\hline $\begin{array}{l}\text { Cantarero e } \\
\text { Pascual (2008) }\end{array}$ & $\begin{array}{l}\text { Espanha ( } 15 \text { regiões)/Efeitos } \\
\text { Fixos e Aleatórios }\end{array}$ & $\begin{array}{l}\text { Proporção de despesas } \\
\text { de saúde dos entes sub- } \\
\text { nacionais em relação a } \\
\text { despesa total em saúde para } \\
\text { todos os níveis de governo. }\end{array}$ & Efeito Positivo. \\
\hline $\begin{array}{l}\text { Uchimura e } \\
\text { Jütting (2009) }\end{array}$ & $\begin{array}{l}\text { China ( } 26 \text { estados)/Efeitos Fi- } \\
\text { xos com erros padrão robustos }\end{array}$ & $\begin{array}{l}\text { Proporção da despesa agre- } \\
\text { gada do condado em relação } \\
\text { à despesa total da província. }\end{array}$ & Efeito Positivo. \\
\hline Akpan (2011) & $\begin{array}{l}\text { Nigéria ( } 36 \text { estados)/ } \\
\text { Efeitos Aleatórios }\end{array}$ & $\begin{array}{l}\text { Proporção de receita do Es- } \\
\text { tado para a receita federal. }\end{array}$ & Efeito Positivo. \\
\hline $\begin{array}{l}\text { Jiménez-Rubio } \\
\text { (2011a) }\end{array}$ & $\begin{array}{l}\text { Canadá ( } 10 \text { províncias)/Efeitos } \\
\text { Fixos com erros padrões robus- } \\
\text { tos }\end{array}$ & $\begin{array}{l}\text { Proporção de despesas } \\
\text { de saúde dos entes sub- } \\
\text { nacionais em relação a } \\
\text { despesa total em saúde para } \\
\text { todos os níveis de governo. }\end{array}$ & Efeito Positivo. \\
\hline $\begin{array}{l}\text { Jiménez-Rubio } \\
\text { (2011b) }\end{array}$ & $\begin{array}{l}\text { Painel de Países (OCDE)/ } \\
\text { Modelo de correção de erros } \\
\text { com dummies de tendência e } \\
\text { ano e erros padrões robustos }\end{array}$ & $\begin{array}{l}\text { A taxa das receitas fiscais } \\
\text { sub-nacionais sobre as re- } \\
\text { ceitas totais das administra- } \\
\text { çôes públicas e a taxa entre } \\
\text { a receita fiscal sub-nacional } \\
\text { e a receita total do governo } \\
\text { geral. }\end{array}$ & Efeito Positivo. \\
\hline Soto et al. (2012) & $\begin{array}{l}\text { Colombia (1080 municípios)/ } \\
\text { Efeitos Fixos com dummies de } \\
\text { ano e erros padrões robustos }\end{array}$ & $\begin{array}{l}\text { Despesas de saúde contro- } \\
\text { ladas localmente como pro- } \\
\text { porção das despesas totais } \\
\text { de saúde. }\end{array}$ & $\begin{array}{l}\text { Efeito Positivo. Maior efeito } \\
\text { em municípios ricos que em } \\
\text { pobres. }\end{array}$ \\
\hline $\begin{array}{l}\text { Cavalieri e } \\
\text { Ferrante (2016) }\end{array}$ & $\begin{array}{l}\text { Itália ( } 20 \text { regiões)/Efeitos } \mathrm{Fi} \text { - } \\
\text { xos com dummies de tendência } \\
\text { região-específica }\end{array}$ & $\begin{array}{l}\text { Grau de autonomia de deci- } \\
\text { são na alocação de receitas } \\
\text { tributárias e dependência de } \\
\text { transferências fiscais do go- } \\
\text { verno central. }\end{array}$ & $\begin{array}{l}\text { Efeito Positivo. Maior efeito } \\
\text { em regiōes mais pobres. }\end{array}$ \\
\hline $\begin{array}{l}\text { Jiménez-Rubio } \\
\text { e García-Gómez } \\
\text { (2017) }\end{array}$ & $\begin{array}{l}\text { Espanha ( } 50 \text { províncias)/ } \\
\text { Modelo de diferenças em dife- } \\
\text { renças com erros padrões robus- } \\
\text { tos }\end{array}$ & $\begin{array}{l}\text { Descentralização fiscal e po- } \\
\text { lítica, atribuindo-se diferen- } \\
\text { tes escalas para as regiões } \\
\text { antes e depois de alterações } \\
\text { no sistema de saúde. }\end{array}$ & $\begin{array}{l}\text { Efeito Positivo. Os benefí- } \\
\text { cios da descentralização se } \\
\text { concentram em regiões mais } \\
\text { ricas e descentralizadas. }\end{array}$ \\
\hline
\end{tabular}

Notas: Por efeito positivo entende-se que a descentralização fiscal teve efeito de reduzir a taxa de mortalidade infantil. 
Uchimura e Jütting (2009), utilizando dados de 26 províncias chinesas no período de 1995 a 2001, relatam que as províncias mais descentralizadas têm melhor desempenho em relação aos resultados da saúde se duas condições forem atendidas: um sistema de transferência funcional for estabelecido entre os níveis da província e do condado; e se a capacidade fiscal dos próprios municípios for reforçada. Duas medidas de descentralização são utilizadas: relação entre a despesa dos condados agregada a nível provincial e a receita própria dos condados agregada a nível provincial (como medida de equilíbrio vertical), e a razão entre a despesa agregada do condado e a despesa total da província.

A estratégia empírica do trabalho de Jimenez-Rubio (201la) foi construída para 10 províncias do Canadá, entre 1979 e 1995, utilizando como medida de descentralização fiscal: a proporção das despesas de saúde dos entes subnacionais em relação à despesa total em saúde para todos os níveis de governo; e como variáveis de controle: o PIB per capita da província, subsídios globais de saúde per capita do governo federal, despesa federal per capita em saúde, despesa municipal per capita em saúde, assistência médica privada per capita. Ele ressalta que a descentralização tem uma influência positiva substancial sobre a eficácia da política pública na melhoria da saúde da população (medida pela mortalidade infantil).

Soto et al. (2012), utilizando dados de 1080 municípios da Colômbia de 1998 a 2007, e construíndo um indicador de descentralização fiscal similar a Jimenez-Rubio (2011a), encontram que a descentralização diminui as TMIs. Todavia, os efeitos nos resultados da saúde melhoram dependendo das condições socioeconômicas das localidades: eles são maiores nos municípios não pobres do que nos municípios pobres. Entre outras variáveis de controle empregadas, destacam-se o percentual de domicílios com necessidades básicas insatisfeitas e nível de urbanização.

Cavalieri e Ferrante (2016) analizam 20 regiões italianas no período de 1996 a 2012. A descentralização é medida por dois indicadores diferentes, o grau de autonomia de decisão na alocação de receitas tributárias e o outro até que ponto as regiões dependem de transferências fiscais do governo central. Seus resultados mostram que uma maior proporção das receitas fiscais geradas e/ou controladas localmente, bem como uma menor dependência de transferência do governo central, estão consistentemente associadas a menores taxas de mortalidade infantil. Além de constatarem que regiões mais pobres apresentam melhores resultados. 
Por fim, Jimenez-Rubio e Garcia-Gomez (2017) exploram um experimento natural para identificar o efeito da descentralização nos resultados de saúde de 50 províncias espanholas entre 1980 e 2010. Os autores baseiam-se no pressuposto de que o momento da descentralização foi conduzido pela identidade cultural das províncias, que supostamente não está correlacionado com os resultados de saúde, para identificar o efeito da descentralização. Os autores estimam o efeito da descentralização nas taxas de mortalidade neonatal e infantil usando um modelo de diferenças em diferenças, no qual as províncias que adotam um sistema de saúde descentralizado em qualquer período $t$ são consideradas tratadas. Os resultados mostram que a descentralização completa, quando as províncias adquirem independência fiscal e política do governo central, tem um impacto significativo nas taxas de mortalidade neonatal e infantil.

Em suma, de certo modo pode-se aventar, com base nos estudos de Soto (2012) e Cavalieri e Ferrante (2016), que há uma expectativa a priori de que regiões mais pobres em países desenvolvidos apresentem impactos positivos e mais relevantes da descentralização fiscal na redução da mortalidade infantil. Ao passo que esse efeito ocorreria de modo inverso em países em desenvolvimento. Assim, este estudo buscará investigar esses efeitos em um contexto de país em desenvolvimento com reconhecidos problemas de desigualdades regionais.

\section{Arcabouço institucional do sistema de saúde público brasileiro}

Uma mudança revelante no direito ao acesso à saúde no Brasil ocorreu com a Constituição Federal de 1988, que determinou a implantação do Sistema Único de Saúde (SUS), prevendo acesso universal e integralidade no atendimento, além da descentralização como princípio da política. Contudo, isso não foi suficiente para garantir a provisão equânime dos serviços de saúde pública no país. Desse modo, dentro da perspectiva do desenvolvimento de ações e serviços públicos de saúde, o Brasil adotou a Emenda Constitucional $\mathrm{n}^{\mathrm{o}} 29$ do ano 2000 como forma de quantificar e monitorar o financiamento das despesas necessárias para a manutenção do sistema de saúde entre os entes federativos. A referida Emenda estabeleceu para os Estados e Municípios, a participação mínima de $12 \%$ e $15 \%$, respectivamente, da alocação de seus recursos na esfera da saúde. Quanto à União, esta deveria 
aplicar na saúde o valor empenhado no ano anterior, mais a variação nominal do Produto Interno Bruto (PIB).

Segundo o Ministério da Saúde do Brasil (2006), a divisão das responsabilidades da gestão e provisão da saúde no país ocorre da seguinte forma: a) A União é o principal financiador da saúde pública no país. Historicamente, metade dos gastos é feita pelo governo federal, a outra metade fica sob responsabilidade dos Estados e Municípios. A União formula políticas nacionais, mas a implementação é feita por seus parceiros (estados, municípios, ONGs e iniciativa privada). Também tem a função de planejar, criar normas, avaliar e utilizar instrumentos para o controle do SUS; b) O governo estadual implementa políticas nacionais e estaduais, além de organizar o atendimento à saúde em seu território. Os estados possuem secretarias específicas para a gestão de saúde; c) O município é o principal responsável pela saúde pública de sua população. O gestor municipal deve aplicar recursos próprios e os repassados pela União e pelo Estado. O município formula suas próprias políticas de saúde e também é um dos parceiros para a aplicação de políticas nacionais e estaduais de saúde. Ele coordena e planeja o SUS em nível municipal, respeitando a normatização federal e o planejamento estadual. Além disso, pode estabelecer parcerias com outros municípios para garantir o atendimento pleno de sua população para procedimentos de complexidade que estejam acima daqueles que pode oferecer.

Com relação à composição das receitas que devem ser alocadas no setor de saúde, em nível estadual, deve-se somar: a) Impostos Estaduais (Imposto sobre Circulação de Mercadorias e Serviços (ICMS), Imposto sobre Propriedade de Veículo Automotor (IPVA), e Impostos sobre herança e doações); b) Transferências da União (cota-parte do Fundo de Participação dos Estados (FPE), cota-parte do IPI-Exportação e transferências da Lei Kandir); c) Imposto de Renda Retido na Fonte; d) Outras Receitas Correntes. Desse total, devem-se subtrair as tranferências constitucionais e legais que são feitas aos municípios (25\% do ICMS, 50\% do IPVA e 25\% do IPI-Exportação). Após esse procedimento, 12\% dessas receitas devem ser gastas com ações e serviços públicos de saúde. Em nível municipal, o orçamento é composto por: a) Impostos Municipais (Imposto Sobre Serviços (ISS), Imposto Predial Territórial Urbano (IPTU), Imposto sobre Tranferência de Bens Imovéis (ITBI)); b) Tranfêrencias da União (cota-parte do Fundo de Participação do Municípios (FPM), cota-parte do Imposto sobre propriedade Territorial Rural (ITR) e transferências da Lei Kandir); c) Imposto de Renda Retido na Fonte; d) Transferências do Estado; e) 
Outras Receitas Correntes. Como dito anteriormente, 15\% dessas receitas municipais devem ser gastas em saúde.

Apesar do maior peso sobre os municípios, o Ministério da Saúde adverte que a relação entre a União, Estados e Municípios não possui uma hierarquização. Os entes federados negociam e entram em acordo sobre ações, serviços, organização do atendimento e outras relações dentro do sistema público de saúde. É o que se chama de pactuação intergestores, ela pode ocorrer na Comissão Intergestora Bipartite (Estados e Municípios) ou na Comissão Intergestora Tripartite (os três entes federados). Collins et al. (2000) reforçam a importância do Estado na provisão de saúde ao afirmar que o imenso tamanho do Brasil e o grande número de municípios no país tornam bastante impraticável pensar que as formas de integração intergovernamental podem ser conduzidas sem um intermediário estadual, dado que muitos dos municípios são muito pequenos para considerá-los como tendo a capacidade de desenvolver sistemas de saúde municipais viáveis. Conforme o autor, devese notar que a descentralização requer um forte nível de ligação intergovernamental em torno da alocação de recursos, planejamento, garantia de qualidade, supervisão técnica e planejamento de recursos humanos.

A Tabela 1 apresenta a estrutura dos gastos em ações e serviços públicos de saúde por ente federativo nos Estados brasileiros. Pode-se observar que houve um crescimento considerável dos gastos em saúde nos três níveis de governo. Destaca-se que entre 2000 e 2013 os gastos municipais e estaduais em ações e serviços públicos de saúde per capita cresceram, respectivamente, cerca de $200 \%$ e $174 \%$. Além disso, esses dados revelam a assimetria da estrutura dos gastos em saúde no Brasil. A título de exemplo, o Governo do Estado do Maranhão gastava apenas 9.91 reais per capita anualmente em ações e serviços públicos de saúde no ano 2000, bem como o estado do Acre que no mesmo ano deteve aproximadamente apenas 10 reais em gastos per capita com saúde oriundos da esfera municipal. 
Tabela 1 - Gasto total per capita em ações e serviços públicos de saúde por ente federativo nos Estados brasileiros, 2000-2013

\begin{tabular}{|c|c|c|c|c|c|c|c|c|c|}
\hline \multirow[b]{2}{*}{ Unidade da Federação } & \multicolumn{3}{|c|}{$\begin{array}{c}\text { Gasto Municipal } \\
\text { per capita }\end{array}$} & \multicolumn{3}{|c|}{$\begin{array}{l}\text { Gasto Estadual } \\
\text { per capita }\end{array}$} & \multicolumn{3}{|c|}{$\begin{array}{c}\text { Gasto Federal } \\
\text { per capita }\end{array}$} \\
\hline & 2000 & 2013 & Variação & 2000 & 2013 & Variação & 2000 & 2013 & Variação \\
\hline TOTAL & 98.37 & 294.87 & $200 \%$ & 94.34 & 258.64 & $174 \%$ & 271.64 & 413.07 & $52 \%$ \\
\hline Acre & 10.01 & 149.90 & $1398 \%$ & 455.40 & 658.56 & $45 \%$ & 313.90 & 257.77 & $-18 \%$ \\
\hline Alagoas & 41.88 & 174.90 & $318 \%$ & 79.13 & 191.71 & $142 \%$ & 227.24 & 260.09 & $14 \%$ \\
\hline Amapá & 22.51 & 127.38 & $466 \%$ & 273.42 & 625.20 & $129 \%$ & 311.43 & 228.89 & $-27 \%$ \\
\hline Amazonas & 82.06 & 221.74 & $170 \%$ & 187.66 & 484.86 & $158 \%$ & 192.45 & 203.08 & $06 \%$ \\
\hline Bahia & 48.22 & 180.36 & $274 \%$ & 66.37 & 161.47 & $143 \%$ & 186.93 & 243.28 & $30 \%$ \\
\hline Ceará & 50.47 & 205.36 & $307 \%$ & 21.42 & 197.42 & $822 \%$ & 218.21 & 238.22 & $09 \%$ \\
\hline Distrito Federal & & & & 183.02 & 760.31 & $315 \%$ & 339.48 & 209.94 & $-38 \%$ \\
\hline Espírito Santo & 87.52 & 282.80 & $223 \%$ & 155.97 & 355.92 & $128 \%$ & 197.53 & 226.73 & $15 \%$ \\
\hline Goiás & 60.84 & 253.68 & $317 \%$ & 80.90 & 238.39 & $195 \%$ & 212.15 & 232.40 & $10 \%$ \\
\hline Maranhão & 42.72 & 169.36 & $296 \%$ & 9.91 & 159.50 & $1509 \%$ & 197.39 & 240.07 & $22 \%$ \\
\hline Mato Grosso & 111.47 & 318.95 & $186 \%$ & 38.92 & 286.26 & $636 \%$ & 232.46 & 233.02 & $0 \%$ \\
\hline Mato Grosso do Sul & 118.33 & 396.13 & $235 \%$ & 105.58 & 308.36 & $192 \%$ & 218.95 & 273.63 & $25 \%$ \\
\hline Minas Gerais & 113.86 & 309.95 & $172 \%$ & 48.24 & 208.53 & $332 \%$ & 201.83 & 245.23 & $22 \%$ \\
\hline Pará & 32.85 & 154.74 & $371 \%$ & 55.66 & 190.73 & $243 \%$ & 188.21 & 203.06 & $08 \%$ \\
\hline Paraíba & 46.54 & 212.00 & $356 \%$ & 31.50 & 225.34 & $615 \%$ & 251.62 & 272.88 & $08 \%$ \\
\hline Paraná & 103.53 & 312.17 & $202 \%$ & 42.90 & 191.16 & $346 \%$ & 219.29 & 259.23 & $18 \%$ \\
\hline Pernambuco & 46.12 & 186.87 & $305 \%$ & 84.03 & 236.83 & $182 \%$ & 251.13 & 262.15 & $04 \%$ \\
\hline Piauí & 26.06 & 207.91 & $698 \%$ & 40.57 & 208.12 & $413 \%$ & 225.50 & 272.70 & $21 \%$ \\
\hline Rio de Janeiro & 106.71 & 342.82 & $221 \%$ & 94.39 & 239.07 & $153 \%$ & 415.61 & 334.91 & $-19 \%$ \\
\hline Rio Grande do Norte & 75.34 & 257.81 & $242 \%$ & 129.87 & 266.31 & $105 \%$ & 236.96 & 260.84 & $10 \%$ \\
\hline Rio Grande do Sul & 100.55 & 299.17 & $198 \%$ & 85.71 & 254.80 & $197 \%$ & 272.01 & 324.99 & $19 \%$ \\
\hline Rondônia & 61.36 & 232.01 & $278 \%$ & 108.84 & 346.03 & $218 \%$ & 319.20 & 212.67 & $-33 \%$ \\
\hline Roraima & 57.37 & 204.64 & $257 \%$ & 364.00 & 758.76 & $108 \%$ & 436.32 & 256.07 & $-41 \%$ \\
\hline Santa Catarina & 89.01 & 337.35 & $279 \%$ & 106.58 & 246.07 & $131 \%$ & 200.95 & 247.03 & $23 \%$ \\
\hline São Paulo & 179.74 & 450.11 & $150 \%$ & 162.69 & 299.64 & $84 \%$ & 218.61 & 221.26 & $01 \%$ \\
\hline Sergipe & 40.72 & 192.41 & $373 \%$ & 43.11 & 295.74 & $586 \%$ & 230.21 & 260.04 & $13 \%$ \\
\hline Tocantins & 71.75 & 221.64 & $209 \%$ & 156.15 & 635.49 & $307 \%$ & 260.33 & 277.95 & $07 \%$ \\
\hline
\end{tabular}

Fonte: DATASUS, Ministério da Saúde do Brasil. Valores deflacionados com base no Índice Nacional de Preços ao Consumidor Amplo (IPCA) 2013. Elaboração Própria.

Por fim, é interessante destacar que a EC 29/2000 pode ter influenciado de forma significativa a dinâmica da descentralização da saúde no Brasil, dado sua regra de transição e critérios exigidos.

Conforme a Tabela 2, para os Estados e os Municípios, até o exercício financeiro de 2004, deveria ser observada a regra de evolução progressiva de aplicação dos percentuais mínimos de vinculação. Os entes federados 
cujo percentual aplicado em 2000 tiverem sido não superior a sete por cento deveriam aumentá-lo de modo a atingir o mínimo previsto para os anos subsequentes.

Tabela 2 - Regra de Transição da Emenda Constitucional N ${ }^{0} 29$.

\begin{tabular}{lcc}
\hline & Percentuais Mínimos de & Vinculação \\
\hline Ano & Estados & Municípios \\
$\mathbf{2 0 0 0}$ & $7 \%$ & $7 \%$ \\
$\mathbf{2 0 0 1}$ & $8 \%$ & $8,6 \%$ \\
$\mathbf{2 0 0 2}$ & $9 \%$ & $10,2 \%$ \\
$\mathbf{2 0 0 3}$ & $10 \%$ & $11,8 \%$ \\
$\mathbf{2 0 0 4}$ & $12 \%$ & $15 \%$ \\
\hline
\end{tabular}

Fonte: Conselho Nacional de Saúde. Resolução N ${ }^{\mathrm{O}} 322$.

A Figura 1 expõe a evolução do indicador de descentralização fiscal da saúde nos estados brasileiros no período de 2000 a 2013. Pode-se observar que nos anos iniciais da série, entre os anos de 2000 e 2005, há um forte crescimento da descentralização dos gastos em saúde na maioria das unidades federativas do país, com relativa estabilidade após esse período. Como dito anteriormente, as razões por trás desta variação podem ser atribuídas em grande medida as alterações implicadas pela mudança de legislação advinda da Emenda Constitucional $\mathrm{N}^{\mathrm{O}} 29$ do ano 2000. Se esse aumento expressivo da descentralização teve efeito similar sobre a saúde infantil ao longo de todo o território nacional, será o objetivo de investigação das próximas seções. 


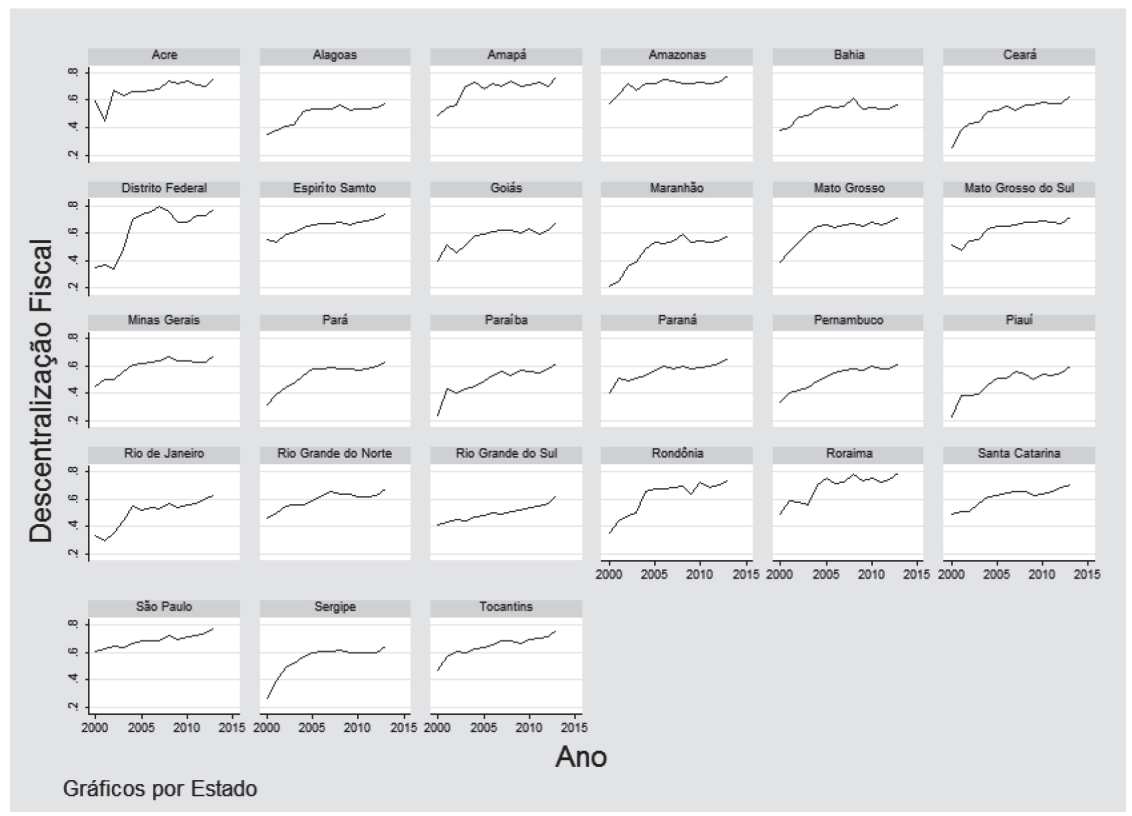

Figura 1 - Evolução do indicador de descentralização fiscal da saúde nos estados brasileiros, 2000-2013

\section{Metodologia}

\subsection{Dados}

Os dados que viabilizaram este estudo foram obtidos em duas fontes. A primeira, o Ministério da Saúde do Brasil, a partir do sistema de compilação de dados DATA-SUS. A segunda, o Instituto Brasileiro de Geografia e Estatística (IBGE), através de dados oriundos da Pesquisa Nacional por Amostra de Domicílios (PNAD). Foram utilizados dados anuais para a taxa de mortalidade infantil até o primeiro e quinto ano de vida, com o intuito de identificar os impactos da descentralização sobre resultados na saúde infantil. ${ }^{6}$

${ }^{6}$ Um aspecto apontado na literatura é o problema de subnotificações de óbitos. Segundo dados de 2003, o Ministério da Saúde (2008) estimou que nas regiões Norte e Nordeste do Brasil ocorreram 95\% do total dos óbitos não declarados no país. Após uma série de mudanças entre os anos de 2005 e 2006 
O painel é formado por 26 Estados brasileiros e o Distrito Federal no período de 2000 a 2013. Destaca-se que a PNAD não foi realizada nos anos de 2000 e 2010. Portanto, são 324 observações que compõem a amostra do trabalho.

A Tabela 3 apresenta uma análise descritiva e definição das variáveis utilizadas. A variável que merece uma maior reflexão e explicação em seu uso e construção é o indicador de descentralização fiscal. Segundo Jimenez-Rubio (2011a) e Soto et al. (2012), a mais usual medida quantitativa disponível de descentralização da assistência de saúde é a proporção entre os gastos de saúde subnacionais para o total de gastos de saúde para todos os níveis de governo. Assim, através dos dados do Ministério da Saúde do Brasil, o cálculo do indicador de descentralização nesse artigo considera o nível de gastos anuais per capita com ações e serviços públicos de saúde, deflacionados com base no Índice Nacional de Preços ao Consumidor Amplo (IPCA) do ano 2013, para os três entes federados do país (União, Estados e Municípios).

Desse modo, levando em consideração as características institucionais do Brasil, o indicador de descentralização da saúde é calculado somando-se os gastos per capita com ações e serviços de saúde pública dos Estados e Municípios, e posteriormente dividindo-o pelo total de gastos per capita em ações e serviços públicos de saúde, que é a soma dos gastos per capita federais, estaduais e municipais. Além disso, destacam-se as outras variáveis de controle obtidas no Ministério da Sáude, uma proxy para gastos privados em saúde: proporção da população com a acesso a assistência médica através de planos privados de saúde; e uma medida de necessidades no período de gestação da criança: baixo peso ao nascer, proporção de nascidos vivos pesando menos que $2.500 \mathrm{~g}$.

As variáveis obtidas no IBGE, através da PNAD, foram o indicador do nível de rendimentos: a renda domiciliar per capita; uma medida de capital social: proporção da população feminina acima de 15 anos de idade alfabetizada; e três indicadores de condições básicas de vida: percentual das pessoas que vivem em domicílios com acesso a um sistema básico de esgoto, ${ }^{7}$

para melhorar a qualidade do Sistema de Informações de Mortalidade - SIM, o Ministério da Saúde conseguiu a permanência do percentual dos óbitos com causa mal definida abaixo de $10 \%$ nas regiões Norte e Nordeste. A estrutura de dados em painel é um paliativo para esse problema.

7 Dados da PNAD 2013 revelam que 25\% da população brasileira não dispõe de condições básicas de esgotamento sanitário. Com esse número se elevando para $47 \%$ e $43 \%$ nas regiões Norte e Nordeste do país, respectivamente. 
percentual de pessoas em domicílios com acesso a água potável através de sistema canalizado e percentual de pessoas em domicílios com acesso ao serviço de coleta de lixo.

Uma primeira inspeção nos dados revela que, como exposto na Figura 2 , há uma relação inversamente proporcional entre a taxa de mortalidade infantil e o indicador de descentralização fiscal da saúde do Brasil no período de 2000 a 2013. Dado que a mortalidade infantil vem reduzindo no país desde os anos $1960^{8}$ e como o processo de crescimento dos gastos em saúde dos entes federados subnacionais iniciou-se apenas no ano 2000, é salutar questionar se a redução da mortalidade na década de 2000 estaria de fato relacionada ao processo de descentralização. Soares (2007a) advoga que a redução da mortalidade infantil no Brasil entre os anos de 1970 e 2000 estaria fortemente relacionada aos ganhos educacionais de sua população, redução da taxa de analfabetismo.

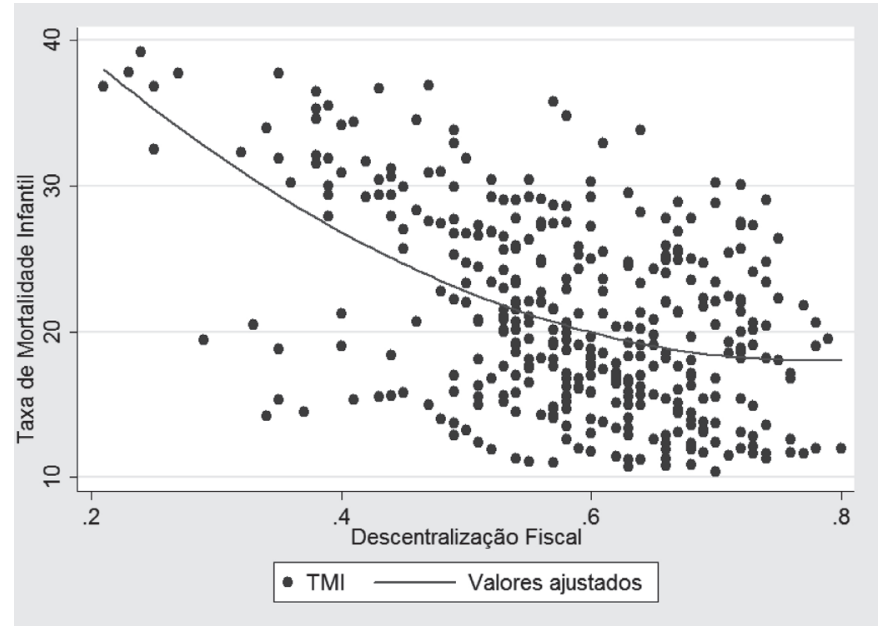

Figura 2 - Evolução da mortalidade infantil e indicador de descentralização fiscal da saúde no Brasil, 2000-2003

8 Soares (2007b) mostra que a América Latina de uma maneira geral reduziu cerca de 70\% a mortalidade infantil (por 1,000 nascidos vivos) entre 1960 e 2000. O Brasil seguiu essa tendência segundo o referido autor. 

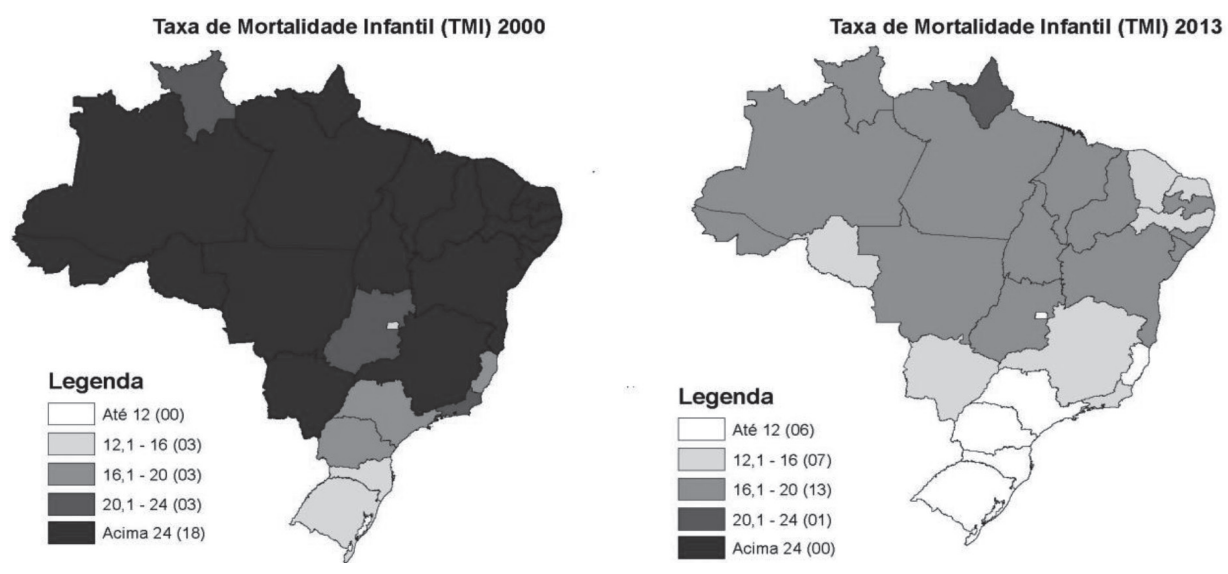

Figura 3 - Evolução Espacial da Mortalidade Infantil nos Estados Brasileiros, 2000-2013.

A Figura 3 apresenta a evolução espacial da taxa de mortalidade infantil nos Estados brasileiros entre 2000 e 2013. Observa-se que há uma tendência comum a todas unidades federativas em reduzir a mortalidade. Entretanto, alguns Estados destacam-se, como: Ceará, Rio Grande do Norte e Pernambuco na região Nordeste; Minas Gerais na região Sudeste; Mato Grosso do Sul na região Centro-Oeste e, Rondônia na região Norte. ${ }^{9}$ Ademais, destaca-se que há maior predominância de taxas mais elevadas de mortalidade infatil até um ano de vida nas regiões Norte e Nordeste do país.

${ }^{9}$ O estado do Ceará foi destaque nacional reduzindo em $62 \%$ a taxa de mortalidade infantil entre os anos de 2000 e 2013. Os estados do Rio Grande do Norte e Pernambuco reduziram, 54\% e 56\%, respectivamente. Minas Gerais, 44\%. Mato Grosso do Sul, 46\% e Rondônia, 53\%. 
Tabela 3 - Análise Descritiva e Definição das Variáveis

\begin{tabular}{|c|c|c|c|c|c|c|c|c|}
\hline \multicolumn{9}{|c|}{ Lista de Variáveis } \\
\hline Variável & Média & Desvio $\mathrm{Pz}$ & adrão & Mín & Máx & Definição & Período & Fonte \\
\hline $\begin{array}{l}\text { Mortalidade } \\
\text { Infantil }\end{array}$ & 21.1 & $\begin{array}{l}\text { Overall } \\
\text { Between } \\
\text { Within }\end{array}$ & $\begin{array}{l}6.67 \\
4.93 \\
4.58\end{array}$ & $\begin{array}{l}10.4 \\
12.7 \\
11.8\end{array}$ & $\begin{array}{l}39.2 \\
27.4 \\
35.6\end{array}$ & $\begin{array}{l}\text { Número de crianças } \\
\text { que morrem antes do } \\
\text { primeiro ano de vida, } \\
\text { expressa como uma } \\
\text { taxa por } 1000 \text { nasci- } \\
\text { das vivas. }\end{array}$ & $2000-2013$ & DATA-SUS \\
\hline $\begin{array}{l}\text { Mortalidade } \\
\text { na Infância }\end{array}$ & 24.5 & $\begin{array}{l}\text { Overall } \\
\text { Between } \\
\text { Within }\end{array}$ & $\begin{array}{l}7.61 \\
5.66 \\
5.20\end{array}$ & $\begin{array}{l}12.1 \\
14.9 \\
13.6\end{array}$ & $\begin{array}{l}44.3 \\
31.0 \\
40.8\end{array}$ & $\begin{array}{l}\text { Número de crianças } \\
\text { que morrem antes } \\
\text { dos cinco anos de } \\
\text { vida, expressa como } \\
\text { uma taxa por } 1000 \\
\text { nascidas vivas. }\end{array}$ & $2000-2013$ & DATA-SUS \\
\hline Descentralização & 0.58 & $\begin{array}{l}\text { Overall } \\
\text { Between } \\
\text { Within }\end{array}$ & $\begin{array}{l}0.11 \\
0.07 \\
0.08\end{array}$ & $\begin{array}{l}0.21 \\
0.47 \\
0.28\end{array}$ & $\begin{array}{l}0.80 \\
0.71 \\
0.75\end{array}$ & $\begin{array}{l}\text { Indicador de Descen- } \\
\text { tralização Fiscal da } \\
\text { Saúde. }\end{array}$ & $2000-2013$ & $\begin{array}{l}\text { Elaboração } \\
\text { do Autor }\end{array}$ \\
\hline $\begin{array}{l}\text { Renda } \\
\text { Domiciliar }\end{array}$ & 730.9 & $\begin{array}{l}\text { Overall } \\
\text { Between } \\
\text { Within }\end{array}$ & $\begin{array}{l}302.9 \\
277.3 \\
132.2\end{array}$ & $\begin{array}{l}314.2 \\
416.8 \\
380.5\end{array}$ & $\begin{array}{l}2034 \\
1632 \\
1133\end{array}$ & $\begin{array}{l}\text { Renda Domiciliar per } \\
\text { capita em reais de } \\
2013 .\end{array}$ & $2001-2013$ & IBGE \\
\hline $\begin{array}{l}\text { Gasto } \\
\text { Estadual }\end{array}$ & 386.4 & $\begin{array}{l}\text { Overall } \\
\text { Between } \\
\text { Within }\end{array}$ & $\begin{array}{l}177.6 \\
124.8 \\
128.4\end{array}$ & $\begin{array}{l}52.63 \\
210.2 \\
55.75\end{array}$ & $\begin{array}{l}963.4 \\
668.5 \\
707.3\end{array}$ & $\begin{array}{l}\text { Gasto Estadual e } \\
\text { Municipal per capita } \\
\text { anual com ações e } \\
\text { serviços de saúde } \\
\text { pública em reais de } \\
2013 \text {. }\end{array}$ & $2000-2013$ & DATA-SUS \\
\hline $\begin{array}{l}\text { Gasto } \\
\text { Federal }\end{array}$ & 247.3 & $\begin{array}{l}\text { Overall } \\
\text { Between } \\
\text { Within }\end{array}$ & $\begin{array}{l}54.0 \\
35.1 \\
41.5\end{array}$ & $\begin{array}{l}149.0 \\
184.7 \\
150.2\end{array}$ & $\begin{array}{l}525.8 \\
359.2 \\
494.5\end{array}$ & $\begin{array}{l}\text { Gasto Federal per ca- } \\
\text { pita anual com açóes } \\
\text { e serviços de saúde } \\
\text { pública em reais de } \\
2013 \text {. }\end{array}$ & $2000-2013$ & DATA-SUS \\
\hline $\begin{array}{l}\text { Plano } \\
\text { de Saúde }\end{array}$ & 13.62 & $\begin{array}{l}\text { Overall } \\
\text { Between } \\
\text { Within }\end{array}$ & $\begin{array}{l}9.16 \\
8.94 \\
2.59\end{array}$ & $\begin{array}{l}2.68 \\
4.56 \\
6.97\end{array}$ & $\begin{array}{l}42.9 \\
39.1 \\
20.2\end{array}$ & $\begin{array}{l}\text { Proporção da popu- } \\
\text { lação coberta por } \\
\text { plano privado de } \\
\text { saúde com assistên- } \\
\text { cia médica. }\end{array}$ & $2000-2013$ & DATA-SUS \\
\hline $\begin{array}{l}\text { Alfabetização } \\
\text { Feminina }\end{array}$ & 87.9 & $\begin{array}{l}\text { Overall } \\
\text { Between } \\
\text { Within }\end{array}$ & $\begin{array}{l}6.09 \\
5.90 \\
1.85\end{array}$ & $\begin{array}{l}71.0 \\
74.9 \\
82.9\end{array}$ & $\begin{array}{l}96.7 \\
95.8 \\
93.4\end{array}$ & $\begin{array}{l}\text { Proporção da popu- } \\
\text { lação feminina acima } \\
\text { de } 15 \text { anos de idade } \\
\text { alfabetizada. }\end{array}$ & $2001-2013$ & IBGE \\
\hline $\begin{array}{l}\text { Baixo Peso ao } \\
\text { Nascer (BPN) }\end{array}$ & 7.72 & $\begin{array}{l}\text { Overall } \\
\text { Between } \\
\text { Within }\end{array}$ & $\begin{array}{l}0.91 \\
0.85 \\
0.36\end{array}$ & $\begin{array}{l}4.10 \\
6.30 \\
5.52\end{array}$ & $\begin{array}{l}9.70 \\
9.44 \\
8.79\end{array}$ & $\begin{array}{l}\text { Proporção de nas- } \\
\text { cidos vivos pesando } \\
\text { menos que } 2500 \mathrm{~g} \text {. }\end{array}$ & $2000-2013$ & DATA-SUS \\
\hline Saneamento & 0.58 & $\begin{array}{l}\text { Overall } \\
\text { Between } \\
\text { Within }\end{array}$ & $\begin{array}{l}0.21 \\
0.19 \\
0.08\end{array}$ & $\begin{array}{l}0.11 \\
0.26 \\
0.30\end{array}$ & $\begin{array}{l}0.97 \\
0.94 \\
0.88\end{array}$ & $\begin{array}{l}\text { Percentual de domi- } \\
\text { cílios com adequado } \\
\text { saneamento através } \\
\text { de rede coletora ou } \\
\text { fossa séptica. }\end{array}$ & 2001-2013 & IBGE \\
\hline Água Potável & 0.85 & $\begin{array}{l}\text { Overall } \\
\text { Between } \\
\text { Within }\end{array}$ & $\begin{array}{l}0.13 \\
0.12 \\
0.05\end{array}$ & $\begin{array}{l}0.45 \\
0.61 \\
0.68\end{array}$ & $\begin{array}{l}1.00 \\
0.99 \\
1.02\end{array}$ & $\begin{array}{l}\text { Percentual de pes- } \\
\text { soas em domicílios } \\
\text { com acesso a aguá } \\
\text { potável através de } \\
\text { sistema canalizado. }\end{array}$ & $2001-2013$ & IBGE \\
\hline Coleta de Lixo & 0.81 & $\begin{array}{l}\text { Overall } \\
\text { Between } \\
\text { Within }\end{array}$ & $\begin{array}{l}0.12 \\
0.11 \\
0.04\end{array}$ & $\begin{array}{l}0.46 \\
0.53 \\
0.68\end{array}$ & $\begin{array}{l}0.99 \\
0.98 \\
0.95\end{array}$ & $\begin{array}{l}\text { Percentual de pes- } \\
\text { soas em domicílios } \\
\text { com acesso ao serviço } \\
\text { de coleta de lixo. }\end{array}$ & $2001-2013$ & IBGE \\
\hline
\end{tabular}

Por fim, ressalta-se que a escolha das variáveis de controle para compor o modelo seguiu o padrão da literatura: Descentralização, Gasto Federal e Baixo Peso ao Nascer (Jimenez-Rubio 2011a); Gasto Estadual e 
Alfabetização Feminina (Asfaw et al. 2007); Plano de Saúde, proposta do autor de utilizar a proporção da população coberta por plano privado de saúde como proxy para o valor do gasto per capita em serviços de saúde providos pelo setor privado, que foi a medida utilizada por JimenezRubio (2011a); Renda Domiciliar, Saneamento, Água Potável e Coleta de Lixo (Soares 2007a e Soto 2012).

\subsection{Modelo econométrico}

A abordagem empírica deste artigo, apesar de se aproximar do padrão na literatura (Jimenez-Rubio 2011), sugere a incorporação de medidas importantes para a realidade de países em desenvolvimento (Soares 2007a e Soto et al. 2012). Dado a estrutura de dados, o método de estimação empregado para testar a direção dos efeitos da descentralização sobre resultados da saúde infantil foi o modelo bidirecional de efeitos fixos com dummies de tendências estado-específicas e erros padrões robustos. ${ }^{10}$ Assim, os modelos de efeito médio nacional (1) e efeitos regionais (2) utilizados podem ser descritos da seguinte forma:

$T M i t=\beta 0+\beta 1$ Descentralizacaoit $+\beta X i t+\alpha i+\theta i T e m p o t+\varepsilon i t$

onde $i=1, \ldots, 27 ; t=2000, \ldots, 2013$

TMit $=\beta 0+\beta j$ Regiao $j *$ Descentralizacaoit $+\beta X i t+\alpha i+\theta i T e m p o t+\varepsilon i t ~(2)$ onde $i=1, \ldots, 27 ; t=2000, \ldots, 2013 \mathrm{e} j=1, \ldots, 5$

A variável dependente, $T M$, denota a taxa de mortalidade infantil (menores de 1 ano) ou na infância (menores de 5 anos) em logarítimo. A variável explicativa de principal interesse é a Descentralização (em logarítimo), indicador de descentralização fiscal da saúde. $\mathrm{O}$ vetor $X$ de variáveis de controle é composto pelas variáveis (em logarítimo): Renda, renda domiciliar per capita; Gasto Estadual, gasto estadual e municipal anual per capita com ações e serviços públicos de s a úde em Reais de 2013; Gasto Federal, gasto federal anual per capita com ações e serviços públicos de saúde em Reais de 2013; PlanodeSaude, proporção da população

\footnotetext{
${ }^{10}$ Para maiores detalhes sobre a metodologia de efeitos fixos bidirecional ver Cameron e Trivedi (2005).
} 
coberta com assistência médica por plano privado de saúde; Alfabetizacao Feminina, taxa de alfabetização entre mulheres de 15 anos ou mais de idade; $B P N$, proporção de nascidos vivos com peso inferior a $2500 \mathrm{~g}$, independente do tempo de gestação; Saneamento, percentual das pessoas que vivem em domicílios com acesso a instalações adequadas de esgoto; Água, percentual de pessoas em domicílios com acesso a água potável; Lixo percentual de pessoas em domicílios com acesso ao serviço de coleta de lixo.

O termo $\alpha_{i}$ (efeito fixo estadual) são os efeitos idiossincráticos que não variam no tempo associados a cada Estado e que podem afetar de alguma maneira os níveis de mortalidade como, por exemplo, as características naturais, as condições climáticas, estrutura econômica, etc. Assim, pode ser entendido como um representante de variáveis omitidas, que apesar de não observáveis, afetam as taxas de mortalidade local. O termo $\theta_{i}$ representa a tendência específica estadual, dummies de tendência para cada Estado da amostra, que permitem controlar qualquer variação sistemática no registro de mortalidade entre Estados em um ponto no tempo, ou através do tempo dentro de um Estado. Como, por exemplo, um programa nacional de saúde familiar lançado pelo governo federal, ou um programa específico de combate a pobreza em um determinado Estado.

Por fim, o componente $\varepsilon_{i t}$ é um termo aleatório com média zero e variância constante. Os subscritos $i, t$ e $j$ correspondem ao Estado, ao período de tempo da observação e a Região do país, respectivamente. Além disso, levando em consideração a possibilidade de erros autocorrelacionados e heterocedásticos, o que poderia acarretar na sobre-estimação da significância dos coeficientes estimados, computaram-se os erros padrões corrigidos para cinco clusters em nível regional. ${ }^{11}$

Ademais, a literatura (Cavalieri e Ferrante 2016; Soto et al. 2012; Robalino et al. 2001) aponta para a existência de evidências de que os efeitos da descentralização fiscal sobre a mortalidade infantil apresente benefícios diferenciados em regiões ou países mais desenvolvidos que em regiões ou países pobres. Então, como exercício adicional e dado que o Brasil é um país que apresenta relevantes disparidades regionais (Assis e Linhares 2018), utilizamse dummies interativas entre determinada região do país e o indicador de descentralização fiscal da saúde (Regiaoj* ${ }^{*}$ escentralizacao $_{\mathrm{it}}$ ) para ter um indicativo dessa hipótese para a economia brasileira.

11 Jiménez-Rubio e García-Gómez (2017) usam estratégia similar para dados da Espanha. 


\section{Resultados preliminares e discussão}

Nesta seção expõem-se os resultados das estimações dispostas de seis formas distintas. Para fins ilustrativos, a Tabela 4 apresenta nas colunas (1) e (4) o modelo similar ao empregado por Jimenez-Rubio (2011) incluindo variáveis de condições básicas de vida e aplicado a mortalidade infantil e na infância, respectivamente. As colunas (2) e (5) incluem aos modelos anteriores dummies de tendências estado-específicas, que permitem a possibilidade de tendências específicas na taxa de mortalidade infantil e na infância para cada Estado, possibilitando amenizar problemas de viés de especificação oriundos da omissão de variáveis relevantes. Nas colunas (3) e (6) são apresentadas as estimações do modelo de efeitos fixos ${ }^{12}$ com dummies de tendências estado-específicas e erros padrões robustos incluindo interações entre determinada região do país e a medida de descentralização fiscal da saúde.

Pode-se observar que os resultados das colunas (1) e (4), estimados com efeitos fixos e erros padrões robustos, apresentam resultados esperados para as variáveis de natureza econômica. Entretanto, as variáveis de caratér social são estatisticamente insignificantes. Isto se deve principalmente ao fato do viés das estimativas ocasionado pela omissão dos efeitos fixos de tendência-específica. Desse modo, dado a estrutura dos dados o modelo apropriado para aferir o impacto da descentralização fiscal sobre resultados da saúde infantil são os expostos nas colunas (2) e (5). Os resultados dessas estimações mostram que a descentralização fiscal das ações e serviços públicos de saúde tiveram estatísticamente impacto em reduzir a taxa de mortalidade infantil e na infância no Brasil entre 2000 e 2013. Os coeficientes estimados das dummies de tendência estado-específicas são conjuntamente significantes (Prob $\geq F=0.00$ ) e sua inclusão tem um efeito marginal substancial sobre o ajustamento do modelo $\left(R^{2}=0.96\right)$. Esse modelo mais conservador revela um efeito médio da descentralização fiscal do setor de saúde de -0.355 na mortalidade infantil e -0.277 na mortalidade na infância, demonstrando maior importância do acesso a serviços de saúde no primeiro ano de vida. Outra evidência que corrobora a importância da maior atenção a fase inicial da vida infantil é o impacto positivo da variável de controle Baixo Peso ao Nascer (BPN), que é uma proxy para necessidades no período de gestação, em ampliar a mortalidade infantil.

12 Como é padrão na literatura, adicionalmente, estimou-se utilizando o modelo de efeitos aleatórios. Porém, o teste de Hausman indicou que o modelo mais apropriado seria o de efeitos fixos. 
Tabela 4 - Resultados das Estimações

\begin{tabular}{|c|c|c|c|c|c|c|}
\hline \multicolumn{7}{|c|}{ Estimador de Efeitos Fixos (E.F.) } \\
\hline (ln) Variável Dependente & \multicolumn{3}{|c|}{ Taxa de Mortalidade Infantil } & \multicolumn{3}{|c|}{ Taxa de Mortalidade na Infância } \\
\hline (ln) Regressores & $(1)$ & $(2)$ & $(3)$ & (4) & $(5)$ & $(6)$ \\
\hline Descentralização & $\begin{array}{c}-0.193^{*} \\
(-2.44)\end{array}$ & $\begin{array}{c}-0.355^{*} \\
(-2.07)\end{array}$ & & $\begin{array}{c}-0.219^{*} \\
(-2.16)\end{array}$ & $\begin{array}{c}-0.277^{*} \\
(-2.05)\end{array}$ & \\
\hline Descentralização $* S$ & & & $\begin{array}{c}-0.598^{* *} \\
(-3.12)\end{array}$ & & & $\begin{array}{c}-0.505^{* *} \\
(-3.58)\end{array}$ \\
\hline Descentralização $* S E$ & & & $\begin{array}{c}-0.379^{* *} \\
(-2.69)\end{array}$ & & & $\begin{array}{c}-0.288^{* *} \\
(-2.83)\end{array}$ \\
\hline Descentralização $* C O$ & & & $\begin{array}{c}-0.452^{*} \\
(-2.54)\end{array}$ & & & $\begin{array}{c}-0.351^{* *} \\
(-2.74)\end{array}$ \\
\hline Descentralização $* N E$ & & & $\begin{array}{c}-0.350^{*} \\
(-2.39)\end{array}$ & & & $\begin{array}{c}-0.268^{*} \\
(-2.44)\end{array}$ \\
\hline Descentralização $* N O$ & & & $\begin{array}{l}-0.245 \\
(-1.21)\end{array}$ & & & $\begin{array}{l}-0.160 \\
(-0.99)\end{array}$ \\
\hline Renda & $\begin{array}{c}-0.133^{* *} \\
(-3.20)\end{array}$ & $\begin{array}{l}-0.096 \\
(-1.56)\end{array}$ & $\begin{array}{l}-0.085 \\
(-1.36)\end{array}$ & $\begin{array}{c}-0.149^{* *} \\
(-3.06)\end{array}$ & $\begin{array}{l}-0.091 \\
(-1.94)\end{array}$ & $\begin{array}{l}-0.081 \\
(-1.65)\end{array}$ \\
\hline $\begin{array}{c}\text { Gasto } \\
\text { Estadual }\end{array}$ & $\begin{array}{c}-0.115^{* *} \\
(-3.85)\end{array}$ & $\begin{array}{r}0.193 \\
(1.47)\end{array}$ & $\begin{array}{l}0.208 \\
(1.78)\end{array}$ & $\begin{array}{c}-0.106^{* *} \\
(-2.67)\end{array}$ & $\begin{array}{l}0.161 \\
(1.47)\end{array}$ & $\begin{array}{l}0.171 \\
(1.81)\end{array}$ \\
\hline $\begin{array}{c}\text { Gasto } \\
\text { Federal }\end{array}$ & $\begin{array}{c}-0.173^{* * *} \\
(-4.25)\end{array}$ & $\begin{array}{c}-0.151^{*} \\
(-2.06)\end{array}$ & $\begin{array}{c}-0.155^{*} \\
(-2.44)\end{array}$ & $\begin{array}{c}-0.185^{* *} \\
(-3.81)\end{array}$ & $\begin{array}{c}-0.116^{*} \\
(-2.09)\end{array}$ & $\begin{array}{c}-0.115^{*} \\
(-2.66)\end{array}$ \\
\hline $\begin{array}{l}\text { Plano de } \\
\text { Saúde }\end{array}$ & $\begin{array}{c}-0.201^{* * *} \\
(-4.36)\end{array}$ & $\begin{array}{l}0.026 \\
(0.36)\end{array}$ & $\begin{array}{l}0.015 \\
(0.23)\end{array}$ & $\begin{array}{c}-0.193^{* * *} \\
(-4.57)\end{array}$ & $\begin{array}{l}0.010 \\
(0.19)\end{array}$ & $\begin{array}{c}0.000 \\
(-0.01)\end{array}$ \\
\hline $\begin{array}{c}\text { Alfabetização } \\
\text { Feminina }\end{array}$ & $\begin{array}{l}-1.427 \\
(-1.86)\end{array}$ & $\begin{array}{l}0.416 \\
(0.69)\end{array}$ & $\begin{array}{l}0.408 \\
(0.67)\end{array}$ & $\begin{array}{l}-1.396 \\
(-1.88)\end{array}$ & $\begin{array}{l}0.329 \\
(0.59)\end{array}$ & $\begin{array}{l}0.320 \\
(0.56)\end{array}$ \\
\hline$B P N$ & $\begin{array}{l}-0.225 \\
(-0.87)\end{array}$ & $\begin{array}{l}0.122^{*} \\
(2.10)\end{array}$ & $\begin{array}{l}0.099^{*} \\
(2.00)\end{array}$ & $\begin{array}{l}-0.210 \\
(-0.92)\end{array}$ & $\begin{array}{l}0.109 \\
(1.14)\end{array}$ & $\begin{array}{l}0.088 \\
(0.99)\end{array}$ \\
\hline Saneamento & $\begin{array}{l}-0.001 \\
(-0.11)\end{array}$ & $\begin{array}{l}-0.001 \\
(-0.09)\end{array}$ & $\begin{array}{l}-0.000 \\
(-0.03)\end{array}$ & $\begin{array}{l}0.000 \\
(0.01)\end{array}$ & $\begin{array}{l}-0.001 \\
(-0.15)\end{array}$ & $\begin{array}{l}-0.001 \\
(-0.08)\end{array}$ \\
\hline Água & $\begin{array}{l}-0.188 \\
(-0.89)\end{array}$ & $\begin{array}{c}-0.080^{* * *} \\
(-4.18)\end{array}$ & $\begin{array}{c}-0.061^{*} \\
(-2.57)\end{array}$ & $\begin{array}{l}-0.169 \\
(-0.88)\end{array}$ & $\begin{array}{c}-0.087^{* * *} \\
(-5.57)\end{array}$ & $\begin{array}{c}-0.070^{*} \\
(-2.43)\end{array}$ \\
\hline Lixo & $\begin{array}{l}0.096 \\
(0.94)\end{array}$ & $\begin{array}{c}-0.078 \\
(-0.69)\end{array}$ & $\begin{array}{l}-0.058 \\
(-0.53)\end{array}$ & $\begin{array}{l}0.106 \\
(0.85)\end{array}$ & $\begin{array}{l}-0.082 \\
(-0.72)\end{array}$ & $\begin{array}{l}-0.062 \\
(-0.55)\end{array}$ \\
\hline Constante & $\begin{array}{c}13.13^{* * *} \\
(5.61)\end{array}$ & $\begin{array}{c}95.51^{* * *} \\
(5.84)\end{array}$ & $\begin{array}{c}96.81^{* * *} \\
(6.71)\end{array}$ & $\begin{array}{c}13.05^{* * *} \\
(5.57)\end{array}$ & $\begin{array}{c}93.78^{* * *} \\
(6.36)\end{array}$ & $\begin{array}{c}94.88^{* * *} \\
(7.33)\end{array}$ \\
\hline E.F. Estado & Sim & Sim & Sim & Sim & Sim & Sim \\
\hline E.F. Estado-Específico Temporal & Não & Sim & Sim & Não & Sim & Sim \\
\hline $\operatorname{Prob} \geq F$ & 0.00 & 0.00 & 0.00 & 0.00 & 0.00 & 0.00 \\
\hline$N$ & 324 & 324 & 324 & 324 & 324 & 324 \\
\hline$R^{2}$ within & 0.88 & 0.96 & 0.96 & 0.89 & 0.97 & 0.97 \\
\hline$R^{2}$ between & 0.68 & 0.25 & 0.33 & 0.68 & 0.19 & 0.28 \\
\hline$R^{2}$ overall & 0.73 & 0.16 & 0.21 & 0.73 & 0.12 & 0.17 \\
\hline
\end{tabular}

Notas: Erros padrões robustos computados em cluster em nível de Região.

${ }^{*}$ significante a $10 \%,{ }^{* *}$ significante a $5 \%,{ }^{* * *}$ significante a $1 \%$. Estatística t entre parênteses. 
Além disso, as regressões das colunas (2) e (5) confirmam a importância dos gastos federais per capita em ações e serviços de saúde, além de demonstrar que o acesso a água potável é um importante fator de infraestrutura domiciliar que afetou a mortalidade infantil e na infância nos Estados brasileiros entre os anos 2000 e 2013. Isso poderia suscitar, em termos de implicações de política, a implementação de cobertura de acesso total dos domicílios do país a água potável. Pode-se destacar a deficiência desse fator no Brasil citando, por exemplo, o estado do Maranhão que no último ano da amostra apresentava 30\% dos seus domicílios sem acesso a água potável. A importância desses vetores também é confirmada pelos resultados de Jimenez-Rubio (2011) e Soto et al. (2012).

As colunas (3) e (6) expõem os resultados com a inclusão das variáveis interativas entre determinada macrorregião e a variável de descentralização. Os coeficientes estimados confirmam que há diferenciais de impacto da descentralização fiscal da saúde entre as regiões do país. A região Sul, que é historicamente a região mais desenvolvida do Brasil, apresentou o mais significativo impacto, um aumento de $10 \%$ da descentralização do setor de saúde acarretaria em, aproximadamente, uma redução de $6 \%$ na taxa de mortalidade infantil. As macrorregiões do Sudeste e Centro-Oeste também apresentaram sinais satisfatórios do efeito da descentralização e estatisticamente significantes ao nível de 5\% e 10\%, respectivamente.

Como relatado por Soto et al. (2012) para dados da Colômbia, as regiões mais pobres detêm efeitos menos robustos da descentralização fiscal sobre a mortalidade infantil. No caso do Brasil, verificou-se essa hipótese através da insignificância estatística da descentralização do setor de saúde na região Norte, região que possui peculiaridades de extensas áreas de mata, cidades isoladas e carência de investimentos em infraestrutura básica que dificultam seu processo de desenvolvimento. A região Nordeste, apesar de também apresentar desafios sociais vis-à-vis outras regiões, parece caminhar em média na direção do restante do país em conseguir impactos positivos de redução na mortalidade infantil e na infância através do processo de descentralização fiscal.

Por fim, as estimativas da coluna (3) mostram que em média um aumento de $10 \%$ na descentralização fiscal da saúde reduziria em aproximadamente $3.5 \%$ a mortalidade infantil no Nordeste brasileiro. Ao primeiro olhar esse resultado parece pouco expressivo, contudo, aumentar nessa magnitude a descentralização significaria apenas uma ampliação da média do indicador 
de 0.58 para 0.64. Dado que o Brasil ainda apresenta razoável nível de centralização, pode-se conseguir isso, por exemplo, simplesmente transferindo 65 reais per capita das obrigações de gastos em saúde do governo federal para os Estados e/ou Municípios. Ademais, a ampliação em 10\% do nível de gastos federais em ações e serviços públicos de saúde reduziria, em média, $1.5 \%$ a mortalidade infantil. A título de informação, segundo dados do periódico Lancet (2017), o Brasil apresenta gasto público em saúde inferior a média global. O país despendiou $8.3 \%$ do PIB para custear a saúde durante o ano de 2014. Todavia, menos da metade desse investimento foi financiado pela esfera pública, já que $54 \%$ corresponderam a gasto privado. Assim, o investimento público do Brasil em Saúde (3.8\%) em percentual do PIB é con- siderado baixo quando comparado a outros países da América Latina. No ano de 2014, por exemplo, a Colômbia destinou 5.4\% do PIB para a Saúde, Equador e Paraguai 4.5\%.

Esses resultados suscitam a necessidade de maior investigação do porquê de efeitos assimétricos da descentralização fiscal do setor de saúde entre as regiões brasileiras. Pode-se elencar como um dos principais desafios da oferta de saúde nas regiões Norte e Nordeste a disponibilidade de recursos humanos, principalmente, na região Norte. Para IPEA (2009), há quatro principais problemas enfrentados pelo SUS no âmbito da administração pública: i) o não cumprimento dos requisitos constitucionais de concurso público para admissão, gerando uma grande quantidade de vínculos que não têm a indispensável base de legalidade, sendo contestáveis pelos órgãos do Ministério Público; ii) as dificuldades para constituir e manter uma adequada diversidade de processos de educação permanente que tenham como efeito não só a qualificação técnica, mas reforcem a adesão dos profissionais ao mo- delo de assistência requerido pelo SUS; iii) a inoperância dos mecanismos de negociação permanente do trabalho entre gestores e entidades representativas dos trabalhadores; e iv) a formação dos profissionais pelas universidades brasileiras, especialmente dos médicos, que privilegia certas especialidades altamente tecnológicas e raramente consegue conferir aos concluintes as habilidades que são requeridas no exercício das funções técnicas e organizacionais peculiares à atenção básica. 


\section{Análise de robustez e sensitividade dos resultados}

Esta seção tem por objetivo buscar investigar a robustez e sensitividade dos resultados encontrados na seção anterior. Assim, seguindo a argumentação proposta por Angrist e Pischke (2009) que propõe a inclusão de defasagens da variável dependente como forma de verificar a robustez de estimativas em modelos de efeitos fixos, o procedimento inicial realizado foi a inclusão de duas defasagens da variável de mortalidade infantil ou na infância na Equação 2. Ademais, como afirma Bond (2002), modelos de efeitos fixos com variáveis defasadas tendem a subestimar as estimativas da regressão. Portanto, essa análise tem a capacidade de fornecer um limite inferior ${ }^{13}$ para os coeficientes que medem o impacto da descentralização das ações e serviços de saúde sobre a mortalidade infantil e na infância.

$$
\begin{aligned}
& \text { TMit }=\beta 0+\lambda 1 T M i, t-1+\lambda 2 T M i, t-2+\beta j \text { Regiaoj } * \text { Descentralizacaoit }+ \\
& \beta X i t+\alpha i+\sigma t+\theta i T t+\varepsilon i t
\end{aligned}
$$

onde $i=1, \ldots, 27 ; t=2000, \ldots, 2013$ e $j=1, \ldots, 5$

Além disso, ainda podem existir fatores não observáveis não capturados pela especificação anterior que podem viesar as estimativas. Desse modo, acrescenta-se também a Equação 3 o termo $\sigma_{t}$, dummies de ano, que medem choques comuns aos estados brasileiros em um determinadado ano específico. Como, por exemplo, uma campanha nacional de vacinação implementada pelo Ministério da Saúde. Por fim, adotou-se o mesmo vetor de variáveis de controle das especificações anteriores, com exceção das variáveis de gastos federais e estaduais per capita em ações e serviços públicos de saúde, que foram substituídas pela inclusão de uma única variável: o valor total dos gastos em ações e serviços públicos de saúde em percentual do PIB do Estado i no ano t. Essa variável também foi construída com informações do Ministério da Saúde do Brasil com o intuito de testar a sensitividade dos resultados, sua utilização é importante pois permite ponderar a capacidade de financiamento do setor público de saúde pelo tamanho da atividade econômica do Estado.

\footnotetext{
${ }^{13}$ Pode-se citar como exemplo Oliveira e Quintana-Domeque (2014), que realizaram o mesmo procedimento para estimar o limite inferior e superior do impacto das condições econômicas ao nascer sobre a estatura da população adulta brasileira.
} 
A Tabela 5 apresenta, de forma resumida, os resultados das estimações de análise de robustez. ${ }^{14}$ Pode-se observar que em geral os resultados encontrados nas colunas (7) e (9) foram similares em sentido aos encontrados pelo modelo proposto como mais adequado. Novamente, a região Sul do país apresentou os mais relevantes e significativos coeficientes de impacto do efeito da descentralização fiscal das ações e serviços públicos de saúde na redução da mortalidade infantil (-0.353) e na infância (- 0.321). Em contrapartida, a região Norte do Brasil exibiu efeito nulo da descentralização sobre a saúde infantil. As demais regiões, Sudeste, Centro-Oeste e Nordeste, também apresentaram estatísticamente efeitos esperados de melhoria da saúde infantil com a descentralização fiscal do setor de saúde. Com relação às variáveis de controle, igualmente ao modelo anterior destaca-se a variável de Baixo Peso ao Nascer. A novidade foi o efeito da renda domiciliar per capita em apresentar efeito de redução nas taxas de mortalidade. Por outro lado, a inclusão da variável de gastos totais em saúde como proporção do PIB não apresentou resultados estatisticamente significativos.

Tabela 5 - Resultados das Estimações de Análise de Robustez.

\begin{tabular}{|c|c|c|c|c|}
\hline \multicolumn{3}{|c|}{ Estimador de Efeitos Fixos (E.F.) } & \multirow{2}{*}{\multicolumn{2}{|c|}{ Taxa de Mortalidade na Infância }} \\
\hline (ln) Variável Dependente & Taxa de $\mathrm{M}$ & idade Infantil & & \\
\hline (ln) Regressores & $(7)$ & $(8)$ & $(9)$ & $(10)$ \\
\hline Descentralização $* S$ & $\begin{array}{c}-0.353^{* * *} \\
(-2.86)\end{array}$ & $\begin{array}{c}-0.281^{* *} \\
(-2.09)\end{array}$ & $\begin{array}{c}-0.321^{* * *} \\
(-2.91)\end{array}$ & $\begin{array}{c}-0.235^{* *} \\
(-2.04)\end{array}$ \\
\hline Descentralização $* S E$ & $\begin{array}{c}-0.114^{* *} \\
(-2.28)\end{array}$ & $\begin{array}{c}0.011 \\
(0.19)\end{array}$ & $\begin{array}{c}-0.097^{* *} \\
(-2.05)\end{array}$ & $\begin{array}{l}0.023 \\
(0.40)\end{array}$ \\
\hline Descentralização $* C O$ & $\begin{array}{c}-0.079^{* *} \\
(-2.50)\end{array}$ & $\begin{array}{l}0.011 \\
(0.37)\end{array}$ & $\begin{array}{c}-0.065^{* *} \\
(-2.26)\end{array}$ & $\begin{array}{l}0.023 \\
(0.81)\end{array}$ \\
\hline Descentralização $* N E$ & $\begin{array}{c}-0.130^{*} \\
(-1.73)\end{array}$ & $\begin{array}{l}-0.022 \\
(-0.38)\end{array}$ & $\begin{array}{l}-0.106 \\
(-1.55)\end{array}$ & $\begin{array}{l}-0.015 \\
(-0.29)\end{array}$ \\
\hline Descentralização $* N O$ & $\begin{array}{c}0.107 \\
(1.13)\end{array}$ & $\begin{array}{l}0.165 \\
(0.81)\end{array}$ & $\begin{array}{c}0.101 \\
(1.23)\end{array}$ & $\begin{array}{l}0.140 \\
(0.90)\end{array}$ \\
\hline E.F. Estado & Sim & Sim & Sim & Sim \\
\hline E.F. Estado-Específico Temporal & Sim & Sim & Sim & Sim \\
\hline E.F. Ano & Sim & Sim & Sim & Sim \\
\hline Mortalidade (2 lags) & Sim & Sim & Sim & Sim \\
\hline Controles Adicionais & Não & Sim & Não & Sim \\
\hline $\operatorname{Prob} \geq F$ & 0.00 & 0.00 & 0.00 & 0.00 \\
\hline$N$ & 270 & 203 & 270 & 203 \\
\hline$R^{2}$ within & 0.98 & 0.98 & 0.98 & 0.98 \\
\hline$R^{2}$ between & 0.37 & 0.08 & 0.30 & 0.04 \\
\hline$R^{2}$ overall & 0.26 & 0.09 & 0.21 & 0.06 \\
\hline
\end{tabular}

Erros padrões robustos computados em cluster em nível de Estado.

${ }^{*}$ significante a $10 \%,{ }^{* *}$ significante a $5 \%,{ }^{* * *}$ significante a $1 \%$. Estatística t entre parênteses. 
Como exercício adicional, as colunas (8) e (10) apresentam os resultados com a inclusão de quatro variáveis de controle adicionais: a proporção de médicos por mil habitantes (uma medida de disponibilidade de recursos humanos - DATASUS); o percentual de nascidos vivos sem nenhuma consulta pré natal (uma medida da qualidade da prestação de serviços de saúde - DATASUS); o percentual de pessoas em situação de pobreza ${ }^{15}$ (que permite controlar o ambiente adverso da ausência de condições básicas de vida - IPEA); e a taxa de urbanização (que possibilita medir efeitos de concentração populacional - IBGE). Embora haja uma perda significativa no tamanho da amostragem devido a restrição de informações dessas novas variáveis de controle, novamente os resultados revelam a robustez dos impactos positivos da descentralização sobre a saúde infantil na região Sul do Brasil. Em suma, os resultados oriundos desta análise corroboram as principais conclusões do trabalho.

\section{Considerações finais}

O presente artigo analisou os efeitos gerais e regionais da descentralização dos serviços de saúde pública sobre a saúde infantil nos Estados brasileiros no período de 2000 a 2013. Para tanto, construiu-se a mais usual medida de descentralização fiscal do setor de saúde indicada por Jimmenez- Rubio (2011a) e Soto et al. (2012): a proporção do gasto per capita em ações e serviços de saúde dos entes sub-nacionais em relação ao gasto total em todos os níveis de governo. Apesar da importância que o acesso a serviços de saúde tem sobre o bem-estar individual e desenvolvimento econômico, pouca atenção tem sido despendida em avaliar os efeitos potenciais da descentralização da saúde em países em desenvolvimento como o Brasil.

Os resultados obtidos através da abordagem empírica do modelo bidirecional de efeitos fixos com dummies de tendência estado-específicas e erros padrões robustos ratificaram que a descentralização fiscal das ações e serviços públicos de saúde tiveram estatísticamente, no período estudado,

\footnotetext{
${ }^{14} \mathrm{Na}$ Tabela 6, em anexo, encontram-se os resultados completos das estimações de análise de robustez dos resultados.

15 Percentual de pessoas na população total com renda domiciliar per capita inferior à linha de pobreza. A linha de pobreza aqui considerada é uma estimativa do custo de uma cesta de alimentos para suprir as necessidades básicas de um indivíduo com base em recomendações da FAO e da OMS.
} 
impacto em reduzir a taxa de mortalidade infantil e na infância no Brasil. Ademais, estimações mais criteriosas confirmaram a importância dos gastos federais per capita em ações e serviços de saúde sobre a mortalidade infantil, além de demonstrar que o acesso à água potável é um importante fator de infra-estrutura domiciliar no contexto brasileiro.

Além disso, a descentralização fiscal da saúde apresenta respostas heterogêneas e consequências distribucionais. Uma vez que seu efeito sobre a mortalidade infantil e na infância é diferenciado, dado o nível de desenvolvimento regional, tendo efeitos mais fortes em regiões mais desenvolvidas, como é o caso do centro-sul brasileiro. Assim, destaca-se a importância de diferenciais institucionais dos governos locais e características populacionais no processo de eficiência da descentralização. Esses resultados corroboram com os encontrados por Soto et al. (2012) para a Colômbia e contribuem com resultados robustos para a reduzida literatura que investiga essa relação no maior país em extensão territorial e em processo de desenvolvimento da América Latina.

Como proposição de política, pode-se argumentar que a descentralização não deve ser interpretada como um objetivo em si, principalmente em regiões que apresentam contextos desfavoráveis como a região Norte do Brasil. O Ministério da saúde precisa reexaminar o instrumento de política para avaliação da capacidade institucional de gestão do setor de saúde dos Estados e Municípios nessa região do país. A eficácia da descentralização requer um forte nível de interação intergovernamental em torno do planejamento de recursos humanos e da alocação de recursos, monitoramento e avaliação dos gastos públicos em ações e serviços de saúde. De modo geral, o Brasil parece caminhar nessa direção, ${ }^{16}$ sendo interessante considerar a possibilidade de continuação de maneira planejada do processo de descentralização fiscal da saúde e aumento do volume de recursos despendidos no setor como forma de melhorar os indicadores de mortalidade infantil, que ainda são bastante desafiadores.

A despeito da forte relação estatística observada neste estudo, a interpretação dos seus resultados em relações de causa e efeito exige cautela. Contudo, esse é um problema padrão e puzzle presente nessa literatura. Outro ponto

${ }^{16}$ De acordo com Marinho et al. (2012), que comparou a eficiência na provisão de serviços de saúde no Brasil com os países da Organização para Cooperação e Desenvolvimento Econômico (OCDE), em termos de eficiência técnica relativa o Brasil apresentou entre 2004 e 2006 um dos melhores desempenhos relativos na provisão de serviços de saúde. 
para futuras investigações é considerar, dado a natureza multidimensional do fenômeno da descentralização, indicadores de descentralização da saúde além do ponto de vista fiscal, apesar da dificuldade empírica de construção. Além disso, deve-se buscar incluir o uso de outras variáveis que mensurem os resultados da saúde infantil, como indicadores de incidência de doenças específicas, por exemplo. Por fim, a despeito dessas limitações, de acordo com as estimações econométricas este trabalho empírico adiciona novas perspectivas de avaliação e análise dos ganhos oriundos dos efeitos gerais e regionais da descentralização fiscal dos serviços de saúde pública sobre a saúde infantil no contexto de países em desenvolvimento, em especial para o caso brasileiro.

\section{Referências}

Angrist, J. D.; Pischke, J. S. Mostly harmless econometrics. Princeton University Press, 2009.

Akpan, E.O. Fiscal decentralization and social outcomes in Nigeria. Eur. J. Bus. Manag 3, no 4: 167-183, 2011. Arrow, K. J. "Uncertainty and the welfare economics of medical care”. American Economic Review 53: 941-973, 1963.

Arzaghi, M. Henderson, J. V. "Why countries are fiscally decentralizing”. Journal of Public Economics 89: 1157-1189, 2005.

Arze del Granado, F.J. Martinez-Vasquez, J. McNab, R. "Fiscal Decentralization and the Functional Composition of Public Expenditures". International Studies Program working papers, 05-01, Georgia State University, Atlanta, USA, 2005.

Asfaw, A. Frohberg, K. James, K.S. et al. "Fiscal decentralization and health outcomes: empirical evidence from rural India”. Journal Developing Areas 41 no 1: 17-35, 2007.

Assis, D. N. C. Linhares, F. C. "Dinâmica da Pobreza, Mudanças Macroecônomicas e Disparidades Regionais no Brasil”. Pesquisa e Planejamento Econômico 48 no 2: 47-96, 2018.

Bond, Stephen. Dynamic panel data models: a guide to micro data methods and practice.

IFS Working Paper CWP09/02, 2002.

Cameron, C. Trivedi, P. Microeconometrics: Methods and Applications. Cambridge University Press, 2005.

Cantarero, D. Pascual, M. "Analysing the impact of fiscal decentralization on health outcomes: empirical evidence from Spain”. Applied Economics Letters 15 no 2: 109-11, 2008.

Cavalieri, M. Ferrante, L. "Does fiscal decentralization improve health outcomes? Evidence from infant mortality in Italy”. Social Science \& Medicine 164: 74-88, 2016.

Collins, C. Araújo, J. Barbosa, J. "Decentralising the health sector: issues in Brazil”. Health Policy 52: 113-127, 2000 .

Faguet, J. "Does Decentralization Increase Responsiveness to Local Needs? Evidence from Bolivia”. World Bank Policy Research Working Paper 2516, Washington D.C, 2001.

Galasso, E. Ravallion M. “Distributional Outcomes of a Decentralized Welfare Program'.

World Bank Policy Research Working Paper 2316, Washington D.C, 2000.

Estud. Econ., São Paulo, vol.50 n.3, p.447-484, jul.-set. 2020 
Guedes, K.P. Gasparine, C. E. "Descentralização Fiscal e o Tamanho do Governo no Brasil".

Economia Aplicada, São Paulo, 11 no 2: 303-323, 2007.

Hayek, F.A. "The use of Knowledge in Society". American Economic Review 35: 453-530, 1945.

Habibi, N. Huang, C. Miranda, D. "Decentralisation and human development in Argentina".

Journal of Human Development 4 no 1: 73-101, 2003.

IPEA. "Políticas sociais: acompanhamento e análise”. Brasília, v. 3, no 17, 2009.

Jiménez-Rubio D. 'The impact of decentralization of health services on health outcomes: evidence from Canada". Applied Economics 43 no 26: 3907-3917, 2011a.

Jiménez-Rubio, D. "The impact of fiscal decentralization on infant mortality rates: evidence from OECD countries". Social Science \& Medicine 73 no 9: 1401-1407, 2011 b.

Jiménez-Rubio, D., García-Gómez, P. "Decentralization of health care systems and health outcomes: Evidence from a natural experiment”. Social Science \& Medicine 188: 69-81, 2017.

Lancet. "Future and potential spending on health 2015-40: development assistance for health, and government, prepaid private, and out-of-pocket health spending in 184 countries". 389: 2005-30, 2017.

Marinho, A. Cardoso, S. S. Almeida, V. V. "Avaliação Comparativa de Sistemas de Saúde com a Utilização de Fronteiras Estocásticas: Brasil e OCDE”. Revisa Brasileira de Economia 66 no 1: 3-19, 2012.

Ministério da Saúde do Brasil. Entendendo o SUS, 2006.

Ministério da Saúde do Brasil. Manual para investigação do óbito com causa mal definida, 2008.

Musgrave, R. A. "The theory of Public Finance". New York: McGraw-Hill, 1959.

Oates, W. E. "Fiscal Federalism, Harcourt Brace Jovanovich”. New York, 1972.

Oates, W.E. "Toward a Second-Generation Theory of Fiscal Federalism”. Int Tax Public Finance 12, 349, 2005.

Oliveira, V. H. Quintana-Domeque, C. "Early-life environment and adult stature in Brazil: An analysis for cohorts born between 1950 e 1980". Economics \& Human Biology v. 15: 67-80, 2014.

Perrson, T. Tabellini, G. "Federal Fiscal Constitutions: Risk Sharing and Moral Hazard".

Econometrica 64: 623-646, 1996a.

Prud'homme, R. "The Dangers of Decentralization”. World Bank Research Observer 10, 201-20, 1995.

Robalino, D.A. Picazo, O.F. Voetberg, A. "Does fiscal decentralization improve health outcomes? Evidence from a cross-country analysis". Policy Research Working Paper 2565, World Bank, Washington, DC, 2001.

Samuelson, P. A. "The Pure Theory of Public Expenditure". The Review of Economics and Statistics 36 no 4: 387-389, 1954.

Shah, A.; Tompson, T. "Implementing Decentralized Local Governance: A Treacherous Road with Potholes, Detours and Road Closures". World Bank Policy Research, 3353, 2004.

Soares, R. R. "Mortality reductions, Educational Attainment, and Fertility Choice".

American Economic Review 95 no 3: 580-601, 2005.

Soares, R. R. "Health and the evolution of welfare across Brazilian municipalities". Journal of Development Economics 84: 590-608, 2007a.

Soares, R. R. "On the Determinants of Mortality Reductions in the Developing World".

Population and Development Review 33 no 2: 247-287, $2007 \mathrm{~b}$.

Soto V.E., Farfan M.I., Lorant V. "Fiscal decentralisation and infant mortality rate: the Colombian case". Social Science \& Medicine 74 no 9: 1426-34, 2012.

Tiebout, C. "A pure theory of local expenditure”. Journal of Political Economy 64: 416-24, 1956.

Uchimura, H. Jutting, J. "Fiscal decentralization, Chinese style: good for health outcomes?"

World Development 37 no 12: 1924-1936, 2009. 


\section{ANEXO A - Gráficos e Tabelas}

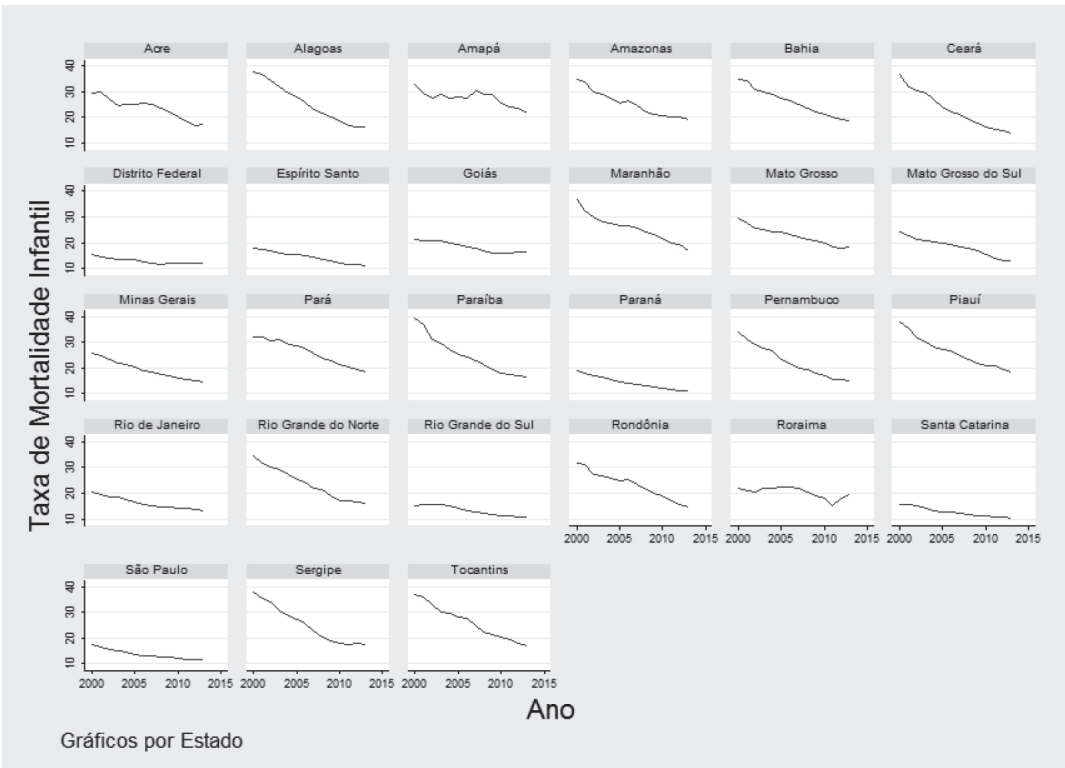

Figura 4 - Evolução da Mortalidade Infantil nos Estados brasileiros, 2000-2013.

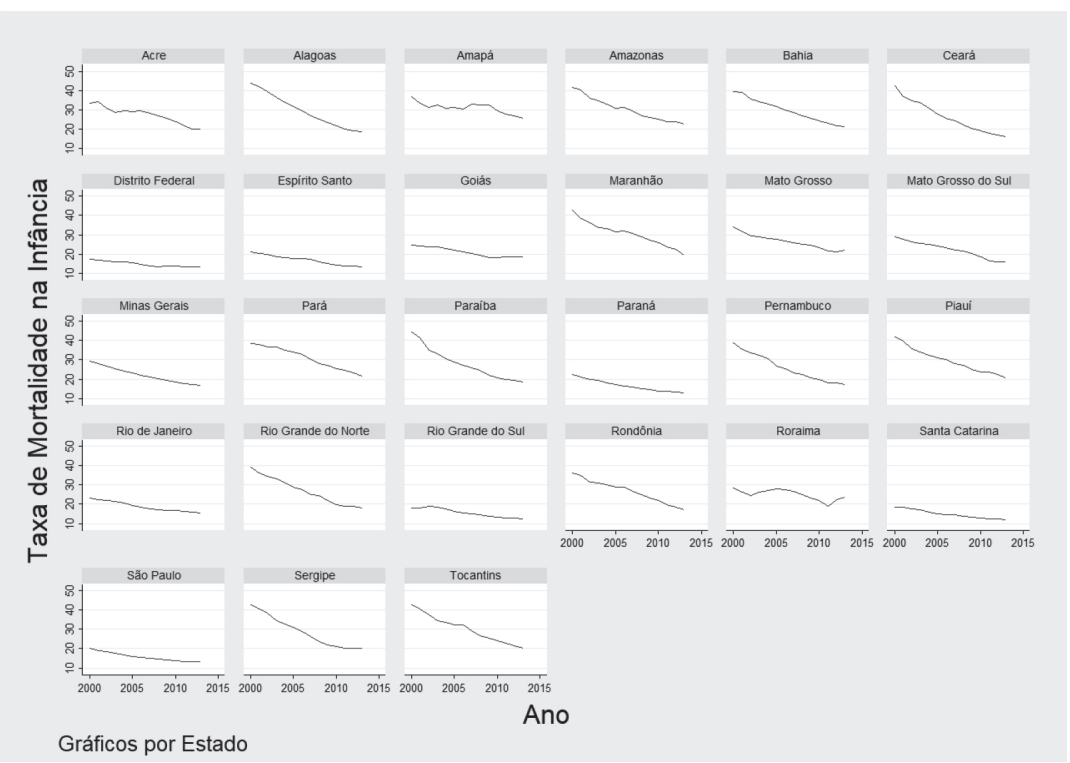

Figura 5 - Evolução da Mortalidade na Infância nos Estados brasileiros, 2000-2013. 
Tabela 6 - Resultados Completos das Estimações de Análise de Robustez.

\begin{tabular}{|c|c|c|c|c|}
\hline \multicolumn{5}{|c|}{ Estimador de Efeitos Fixos (E.F.) } \\
\hline (In) Variável Dependente & Taxa de $\mathrm{M}$ & idade Infantil & Taxa de & ade na Infância \\
\hline (In) Regressores & (7) & $(8)$ & (9) & (10) \\
\hline Descentralização $* S$ & $\begin{array}{c}-0.353^{* * *} \\
(-2.86)\end{array}$ & $\begin{array}{c}-0.281^{* *} \\
(-2.09)\end{array}$ & $\begin{array}{c}-0.321^{* * *} \\
(-2.91)\end{array}$ & $\begin{array}{c}-0.235^{* *} \\
(-2.04)\end{array}$ \\
\hline Descentralização $* S E$ & $\begin{array}{c}-0.114^{* *} \\
(-2.28)\end{array}$ & $\begin{array}{l}0.011 \\
(0.19)\end{array}$ & $\begin{array}{c}-0.097^{* *} \\
(-2.05)\end{array}$ & $\begin{array}{l}0.023 \\
(0.40)\end{array}$ \\
\hline Descentralização $* C O$ & $\begin{array}{c}-0.079^{* *} \\
(-2.50)\end{array}$ & $\begin{array}{l}0.011 \\
(0.37)\end{array}$ & $\begin{array}{c}-0.065^{* *} \\
(-2.26)\end{array}$ & $\begin{array}{l}0.023 \\
(0.81)\end{array}$ \\
\hline Descentralização $* N E$ & $\begin{array}{l}-0.130 \\
(-1.73)\end{array}$ & $\begin{array}{l}-0.022 \\
(-0.38)\end{array}$ & $\begin{array}{l}-0.106 \\
(-1.55)\end{array}$ & $\begin{array}{l}-0.015 \\
(-0.29)\end{array}$ \\
\hline Descentralização $* N O$ & $\begin{array}{l}0.107 \\
(1.13)\end{array}$ & $\begin{array}{l}0.165 \\
(0.81)\end{array}$ & $\begin{array}{l}0.101 \\
(1.23)\end{array}$ & $\begin{array}{l}0.140 \\
(0.90)\end{array}$ \\
\hline$T M I_{t-1}$ & $\begin{array}{c}0.560^{* * * *} \\
(4.46)\end{array}$ & $\begin{array}{c}0.225^{* *} \\
(2.19)\end{array}$ & $\begin{array}{c}0.534^{* * *} \\
(4.50)\end{array}$ & $\begin{array}{c}0.231^{* *} \\
(2.30)\end{array}$ \\
\hline$T M I_{t-2}$ & $\begin{array}{l}-0.160 \\
(-1.88)\end{array}$ & $\begin{array}{c}-0.206^{* *} \\
(-2.31)\end{array}$ & $\begin{array}{l}-0.116 \\
(-1.38)\end{array}$ & $\begin{array}{l}-0.141 \\
(-1.55)\end{array}$ \\
\hline Renda & $\begin{array}{c}-0.078^{* *} \\
(-2.35)\end{array}$ & $\begin{array}{l}-0.010 \\
(-0.30)\end{array}$ & $\begin{array}{c}-0.088^{* *} \\
(-2.64)\end{array}$ & $\begin{array}{l}0.000 \\
(0.00)\end{array}$ \\
\hline $\begin{array}{c}\text { Gasto Total/ } \\
\text { PIB }\end{array}$ & $\begin{array}{l}0.043 \\
(0.73)\end{array}$ & $\begin{array}{l}-0.004 \\
(-0.10)\end{array}$ & $\begin{array}{l}0.037 \\
(0.72)\end{array}$ & $\begin{array}{l}-0.006 \\
(-0.16)\end{array}$ \\
\hline $\begin{array}{l}\text { Plano de } \\
\text { Saúde }\end{array}$ & $\begin{array}{l}0.003 \\
(0.04)\end{array}$ & $\begin{array}{l}-0.073 \\
(-1.20)\end{array}$ & $\begin{array}{l}-0.008 \\
(-0.14)\end{array}$ & $\begin{array}{l}-0.075 \\
(-1.27)\end{array}$ \\
\hline $\begin{array}{l}\text { Alfabetização } \\
\text { Feminina }\end{array}$ & $\begin{array}{l}0.681 \\
(1.83)\end{array}$ & $\begin{array}{l}-0.384 \\
(-1.41)\end{array}$ & $\begin{array}{l}0.648 \\
(1.76)\end{array}$ & $\begin{array}{l}-0.438 \\
(-1.82)\end{array}$ \\
\hline$B P N$ & $\begin{array}{c}0.289^{* * *} \\
(2.93)\end{array}$ & $\begin{array}{l}0.110 \\
(1.07)\end{array}$ & $\begin{array}{c}0.263^{* * *} \\
(2.81)\end{array}$ & $\begin{array}{l}0.078 \\
(0.88)\end{array}$ \\
\hline Saneamento & $\begin{array}{l}0.004 \\
(0.36)\end{array}$ & $\begin{array}{l}0.016 \\
(0.97)\end{array}$ & $\begin{array}{l}0.003 \\
(0.34)\end{array}$ & $\begin{array}{l}0.012 \\
(0.77)\end{array}$ \\
\hline Água & $\begin{array}{l}-0.059 \\
(-0.90)\end{array}$ & $\begin{array}{l}0.145 \\
(1.88)\end{array}$ & $\begin{array}{l}-0.071 \\
(-1.05)\end{array}$ & $\begin{array}{l}0.112 \\
(1.58)\end{array}$ \\
\hline Lixo & $\begin{array}{l}-0.014 \\
(-0.20)\end{array}$ & $\begin{array}{l}-0.163 \\
(-0.74)\end{array}$ & $\begin{array}{l}-0.024 \\
(-0.40)\end{array}$ & $\begin{array}{l}-0.141 \\
(-0.77)\end{array}$ \\
\hline Médicos & & $\begin{array}{c}-0.136^{* *} \\
(-2.10)\end{array}$ & & $\begin{array}{c}-0.130^{* *} \\
(-2.09)\end{array}$ \\
\hline Pré Natal & & $\begin{array}{l}-0.002 \\
(-0.27)\end{array}$ & & $\begin{array}{l}-0.006 \\
(-0.57)\end{array}$ \\
\hline Pobreza & & $\begin{array}{l}0.019 \\
(0.61)\end{array}$ & & $\begin{array}{l}0.017 \\
(0.53)\end{array}$ \\
\hline Urbanização & & $\begin{array}{l}0.190 \\
(0.79)\end{array}$ & & $\begin{array}{l}0.139 \\
(0.60)\end{array}$ \\
\hline E.F. Estado & Sim & Sim & Sim & Sim \\
\hline E.F. Estado-Específico Temporal & Sim & Sim & $\operatorname{sim}$ & Sim \\
\hline E.F. Ano & $\operatorname{Sim}$ & $\operatorname{Sim}$ & $\operatorname{Sim}$ & $\operatorname{Sim}$ \\
\hline Prob $\geq F$ & 0.00 & 0.00 & 0.00 & 0.00 \\
\hline$N$ & 270 & 203 & 270 & 203 \\
\hline$R^{2}$ within & 0.98 & 0.98 & 0.98 & 0.98 \\
\hline$R^{2}$ between & 0.37 & 0.08 & 0.30 & 0.04 \\
\hline$R^{2}$ overall & 0.26 & 0.09 & 0.21 & 0.06 \\
\hline
\end{tabular}

Erros padrões robustos computados em cluster em nível de Estado. Estatística $t$ entre parênteses.

${ }^{* *}$ significante a $5 \%,{ }^{* * *}$ significante a $1 \%$. 


\section{ANEXO B - Descrição das Variáveis de Gastos em Saúde}

As variáveis de gastos em saúde são oriundas do Ministério da Saúde, área de Economia da Saúde e Desenvolvimento, mais precisamente do Sistema de Informações sobre Orçamentos Públicos em Saúde - SIOPS (Gasto Estadual e Municipal); SPO/SE e Fundo Nacional de Saúde - FNS (Gasto Federal). Os valores dos gastos per capita estão apresentados em reais com base no Índice Nacional de Preços ao Consumidor Amplo (IPCA) de dezembro do último ano (2013).

Até o ano de 2008, os gastos estaduais com ações e serviços públicos de saúde eram extraídos das Notas Técnicas da Análise dos Balanços Gerais dos estados de acordo com a Lei $\mathrm{N}^{\mathrm{O}} 4.320,64$, elaboradas pela equipe responsável pelo SIOPS, em conformidade com a Resolução $n^{\mathrm{O}} 322$ do Conselho Nacional de Saúde - CNS e a Emenda Constitucional no 29/2000 - EC 29/00. A partir do ano de 2009 os gastos estaduais passam a ser os declarados no SIOPS.

As despesas com Ações e Serviços Públicos de Saúde são aquelas definidas na quinta e sexta diretrizes da Resolução no 322/2003 do Conselho Nacional de Saúde, descrita em detalhes a seguir. No âmbito federal, além da exclusão da despesa com inativos e pensionistas, foram excluídas as despesas com o pagamento de juros e amortização da dívida e com o Fundo de Erradicação e Combate à Pobreza. A partir de junho de 2004, a despesa com pessoal do Ministério da Saúde executada pelos Estados foi centralizada no Distrito Federal. Para minimizar a distorção do gasto público federal com saúde entre os estados optou-se por contabilizar esta despesa com pessoal na rubrica "Nacional".

\section{CONSELHO NACIONAL DE SAÚDE RESOLUÇÃO No 322, DE 08 DE MAIO DE 2003 DAS AÇÕES E SERVIÇOS PÚBLICOS DE SAÚDE}

Quinta Diretriz: Para efeito da aplicação da Emenda Constitucional n ${ }^{0} 29$, consideram-se despesas com ações e serviços públicos de saúde aquelas com pessoal ativo e outras despesas de custeio e de capital, financiadas pelas três esferas de governo, conforme o disposto nos artigos 196 e 198, $\S 2^{\circ}$, da Constituição Federal e na Lei $n^{\circ} 8080 / 90$, relacionadas a programas finalísticos e de apoio, 
inclusive administrativos, que atendam, simultaneamente, aos seguintes critérios:

I - sejam destinadas às ações e serviços de acesso universal, igualitário e gratuito;

II - estejam em conformidade com objetivos e metas explicitados nos Planos de Saúde de cada ente federativo;

III - sejam de responsabilidade específica do setor de saúde, não se confundindo com despesas relacionadas a outras políticas públicas que atuam sobre determinantes sociais e econômicos, ainda que com reflexos sobre as condições de saúde.

§ Único - Além de atender aos critérios estabelecidos no caput, as despesas com ações e serviços de saúde, realizadas pelos Estados, Distrito Federal e Municípios deverão ser financiadas com recursos alocados por meio dos respectivos Fundos de Saúde, nos termos do Art. 77, $\S 3^{\circ}$ do ADCT.

Sexta Diretriz: Atendido ao disposto na Lei 8.080/90, aos critérios da Quinta Diretriz e para efeito da aplicação da EC 29, consideram-se despesas com ações e serviços públicos de saúde as relativas à promoção, proteção, recuperação e reabilitação da saúde, incluindo:

I - vigilância epidemiológica e controle de doenças;

II - vigilância sanitária;

III - vigilância nutricional, controle de deficiências nutricionais, orientação alimentar, e a segurança alimentar promovida no âmbito do SUS;

IV - educação para a saúde;

V - saúde do trabalhador;

VI - assistência à saúde em todos os níveis de complexidade;

VII - assistência farmacêutica;

VIII - atenção à saúde dos povos indígenas;

IX - capacitação de recursos humanos do SUS;

$\mathrm{X}$ - pesquisa e desenvolvimento científico e tecnológico em saúde, promovidos por entidades do SUS; 
XI - produção, aquisição e distribuição de insumos setoriais específicos, tais como medicamentos, imunobiológicos, sangue e hemoderivados, e equipamentos;

XII - saneamento básico e do meio ambiente, desde que associado diretamente ao controle de vetores, a ações próprias de pequenas comunidades ou em nível domiciliar, ou aos Distritos Sanitários Especiais Indígenas (DSEI), e outras ações de saneamento a critério do Conselho Nacional de Saúde;

XIII - serviços de saúde penitenciários, desde que firmado Termo de Cooperação específico entre os órgãos de saúde e os órgãos responsáveis pela prestação dos referidos serviços.

XIV - atenção especial aos portadores de deficiência.

XV - ações administrativas realizadas pelos órgãos de saúde no âmbito do SUS e indispensáveis para a execução das ações indicadas nos itens anteriores;

$\S 1^{0}$ No caso da União, excepcionalmente, as despesas com ações e serviços públicos de saúde da União financiadas com receitas oriundas de operações de crédito contratadas para essa finalidade poderão integrar o montante considerado para o cálculo do percentual mínimo constitucionalmente exigido, no exercício em que ocorrerem.

$\S 2{ }^{\mathbf{o}}$ No caso dos Estados, Distrito Federal e Municípios, os pagamentos de juros e amortizações decorrentes de operações de crédito contratadas a partir de 01.2000 para custear ações e serviços públicos de saúde, excepcionalmente, poderão integrar o montante considerado para o cálculo do percentual mínimo constitucionalmente exigido.

Sétima Diretriz: Em conformidade com o disposto na Lei 8.080/90, com os critérios da Quinta Diretriz e para efeito da aplicação da $E C$ n $^{0} 29$, não são consideradas como despesas com ações e serviços públicos de saúde as relativas a:

I - pagamento de aposentadorias e pensões;

II - assistência à saúde que não atenda ao princípio da universalidade (clientela fechada);

III - merenda escolar;

IV - saneamento básico, mesmo o previsto no inciso XII da Sexta Diretriz, realizado com recursos provenientes de taxas ou tarifas e do 
Fundo de Combate e Erradicação da Pobreza, ainda que excepcionalmente executado pelo Ministério da Saúde, pela Secretaria de Saúde ou por entes a ela vinculados;

V - limpeza urbana e remoção de resíduos sólidos (lixo);

VI - preservação e correção do meio ambiente, realizadas pelos órgãos de meio ambiente dos entes federativos e por entidades não governamentais;

VII - ações de assistência social não vinculadas diretamente a execução das ações e serviços referidos na Sexta Diretriz e não promovidas pelos órgãos de Saúde do SUS;

VIII - ações e serviços públicos de saúde custeadas com recursos que não os especificados na base de cálculo definida na primeira diretriz.

$\S \mathbf{1}^{\mathbf{O}}$ No caso da União, os pagamentos de juros e amortizações decorrentes de operações de crédito, contratadas para custear ações e serviços públicos de saúde, não integrarão o montante considerado para o cálculo do percentual mínimo constitucionalmente exigido.

$\S 2^{\mathbf{O}}$ No caso dos Estados, Distrito Federal e Municípios, as despesas com ações e serviços públicos de saúde financiadas com receitas oriundas de operações de crédito contratadas para essa finalidade não integrarão o montante considerado para o cálculo do percentual mínimo constitucionalmente exigido, no exercício em que ocorrerem. 